\title{
Experimental Investigations into the Adsorption Enhancement in Packed Beds using Z-Annular Flow Configuration
}

\author{
Yeboah S. K. \\ Department of Architecture and Built Environment, \\ Faculty of Science and Engineering, \\ The University of Nottingham Ningbo China, \\ 199 Taikang East Road, Ningbo 315100, PR China, \\ Email: Siegfried.yeboah@nottingham.edu.cn \\ Darkwa, J. \\ Faculty of Engineering, \\ The University of Nottingham, \\ University Park, Nottingham, NG7 2RD, UK \\ Email: J.Darkwa@nottingham.ac.uk
}

\begin{abstract}
Annular packed bed structures have the potential to overcome limitations of conventional fully packed bed types by offering radial distribution of airflow within them to enhance fluid-solid contact during adsorption and also to minimize pressure drops. In this paper, Z-annular flow configuration is experimentally investigated to evaluate its potential to enhance adsorption. Three typical diametrical ratios (Do/Di) corresponding to 2, 2.35 and 3.08, inferred from literature were used to investigate the adsorption performance of the Z-annular flow arrangement and compared with adsorption performance of a conventionally configured fully packed bed system of similar dimensions.

The results showed the Z-annular flow configurations did perform better by achieving bed temperature reductions averaging between $4.22-5.47^{\circ} \mathrm{C}$ than conventional configuration types. Pressure drops were however observed to be relatively higher in the Z-annular flow configuration bed types than the conventional fully packed bed type due to the endplate in the Z-annular flow configuration impeding the airflow and subsequently causing flow reversal. Overall, the Zannular flow configuration was found to have the potential to enhance the adsorption capacity of packed beds however further investigation on optimum parameters for this enhancement may be required.
\end{abstract}

Key words: heat and mass transfer, physical adsorption, packed beds, pressure drop 


\section{Nomenclature}

- $A=$ cross sectional area of the packed bed $\left(\mathrm{m}^{2}\right)$

- $C_{p g}$ the specific heat of silica gel (kJ/kg)

- $c p_{s}=$ the specific heat of air at constant pressure $(\mathrm{kJ} / \mathrm{kg} \mathrm{K})$

- $c p_{w}=$ the specific heat of water content in the bed $(\mathrm{kJ} / \mathrm{kg} \mathrm{K})$

- $f_{s}=$ dimensionless enhancement factor

- $L=$ the bed length $(\mathrm{m})$

- $m_{g}=$ the air mass flow rate $(\mathrm{kg} / \mathrm{s})$

- $m_{s}=$ the weight of dry silica gel bed $(\mathrm{kg})$

- $p=$ ambient pressure $(\mathrm{kPa})$

- $p_{v}=$ water vapour pressure $(\mathrm{kPa})$

- $p_{g}=$ saturated water vapour pressure $(\mathrm{kPa})$

- $\quad \mathrm{RH}=$ relative humidity $(\%)$

- $Q_{v}=$ volume flow rate $\left(\mathrm{m}^{3} / \mathrm{s}\right)$

- $T_{g i}=$ the air temperature at the bed inlet (K)

- $T_{p}=$ the bed temperature $(\mathrm{K})$

- $u_{o}=$ the superficial air velocity flowing in the bed $(\mathrm{m} / \mathrm{s})$

- $W=$ the water content of silica gel $(\mathrm{kg} / \mathrm{kg})$

Greek Letters

- $\varepsilon=$ the void fraction of silica gel particle

- $\rho_{g}=$ the air density $\left(\mathrm{kg} / \mathrm{m}^{3}\right)$

- $\rho_{s}=$ the dry silica gel density $\left(\mathrm{kg} / \mathrm{m}^{3}\right)$

- $\omega_{\text {in }}$ and $\omega_{\text {out }}=$ the inlet and outlet humidity ratios $(\mathrm{kg} / \mathrm{kg})$

- $\omega$ is humidity ratio/moisture content $(\mathrm{kg} / \mathrm{kg})$

- $\omega_{s}=$ saturated moisture content $(\mathrm{kg} / \mathrm{kg})$

- $\theta=$ temperature, greater than or equal to $0^{\circ} \mathrm{C}\left({ }^{\circ} \mathrm{C}\right)$.

\section{Abbreviations}

- Di - Inner Diameter

- Do - Outer Diameter

- FPB - Fully Packed Bed

- $\quad$ LAPB - Large Annulus Packed Bed

- MAPB - Medium Annulus Packed Bed

- MTZ - Mass Transfer Zone

- SAPB - Small Annulus Packed Bed

- $\mathrm{TC}$ - Thermocouple 


\section{Introduction}

Packing structure within packed beds impacts on the local fluid, heat, and mass transport, which in turn influences macroscopic parameters during adsorption process ${ }^{1}$. Optimum design of adsorption systems therefore crucially requires consideration for the mechanisms of heat and mass transfer, the flow and pressure drop of the fluid through the bed of solid particles ${ }^{2}$. Ineffective fluid-solid contact due to mal-distribution of flow within fully packed beds leads to inefficient adsorption process whilst associated high pressure drops results in excessive energy demands from the blower ${ }^{3}$. Despite channelling effects in randomly packed beds, influence of sorption heat for instance on adsorption processes tend to dominate conventional fully packed bed configuration ${ }^{4}$. According to Awad et $\mathrm{al}^{5}$ for adsorption in solid desiccant packed beds, reducing the distance travelled by air may improve the operation of the trailing layers and provide more efficient use of the whole amount of solid desiccants.

Packed beds when configured into annular structure have been found to have the potential to reduce the overall pressure drop although this structure also impacts on residence time distribution of flow between the inner circular manifold and the outer annular manifold via the annular packing matrix ${ }^{6}$. According to Heggs et $\mathrm{l}^{6}{ }^{6}$ the crucial features that affects the flow characteristics in annular packed bed structures include radial dimensions of the inlet and outlet manifolds, axial bed length, surface friction factors associated with the inlet and outlet manifolds, characteristic parameters of the bed packing and the flow rate and direction of flow. Here, particles of smaller diameters along with kinetically determined adsorption processes can be used as they increase the mass transfer rate creating sharper adsorption fronts offering the potential to use smaller equipment ${ }^{7}$. du Toit ${ }^{8}$ for instance varied the inner and outer diameters of their annular packed bed and found very little difference between the way in which the porosity (which influences the heat transfer phenomena in the bed) varied in the radial direction away from the inner and the outer walls. Kwapinski et $\mathrm{al}^{4}$ designed an annular bed where a cooling candle was installed into the cylindrical column to control the temperature in the centre of the bed. The channelling was dependent on the ratio between the width of the annular gap and the particle diameter. They expected that the annular configuration would show faster breakthrough at the wall than in the core not only by decrease of the thermal effect, but also by increase of flow mal-distribution due to the second wall and the very small ratio between width of the annular gap and particle diameter. However, they found that although the thermal effects were strongly decreased, breakthrough was not faster in the wall region with concentration differences between wall and core region found to be very small. They also found that at a ratio of 3 between annular gap width and particle diameter the hardly damped oscillations of the radial porosity profile that reach the centre of the annular gap lead to operating conditions closely resembling those of plug-flow. Tierney et $\mathrm{al}^{7}$ studied gas movement through an annular packed bed bounded on two sides by unobstructed distributors using experiment and CFD codes and found that the amount of skewness depends on the direction of flow and is higher for inward flow. Hamed et $\mathrm{al}^{9}$ theoretically and experimentally investigated the transient coupled heat and mass transfer in a radial flow activated alumina packed bed using a hollow cylindrical vessel as a desiccant dehumidifier and found that the configuration decreases the required power to blow air through the bed. Awad et $\mathrm{al}^{5}$ theoretically and experimentally investigated a radial flow (annulus) silica gel packed bed dehumidifier using test units of hollow cylindrical bed with different values of diameter ratios. For all the units used in the investigations, the total mass of dry silica gel in the bed was nearly the same. They found that increase in diameter ratio (Do/Di) increases the pressure drop within the bed and raises the bed adsorption capacity for short operational periods. Yeboah and Darkwa ${ }^{10}$ found that optimum packing structure to ensure uniform flow distribution and residence time can potentially lead to effective fluidsolid contact during adsorption in a solid desiccant packed bed dehumidifier. A comparison of radial-flow and axial-flow packed beds for thermal energy storage carried out by McTigue and White ${ }^{11}$ shows that radial-flow stores typically achieve 
lower pressure losses, but typically exhibit steeper thermal fronts which increases thermal and conductive losses. According to Iranshahi et $\mathrm{al}^{12}$, one of the drawbacks of conventional tubular reactors is unfavourable pressure drop, which causes the decline of the reaction rates and conversions. Hence, they proposed a novel radial flow spherical packed bed reactor (RF-SPBR) for auto thermal steam reforming of methane although they also assert that utilising radial-flow tubular reactors can also resolve the problems with conventional tubular reactors. Heggs et $\mathrm{al}^{6}$ theoretically developed models to predict gas flow distribution in annular packed beds based on the basic assumption of uni-radial flow. The purpose was to establish a two-dimensional model for the prediction of flow distribution in annular packed beds for isothermal, steadystate convective flow, with no chemical reaction or adsorption involved. From their results, they found that for both the normal and reverse Z-annular flow arrangements, the radial flow increases progressively with distance along the bed measured from the end at which the gas enters. Heggs et al ${ }^{3}$ later experimentally investigated the Z-annular flow arrangement using a carbon bed layer and found that the positioning of the main carbon bed layer affects both the total pressure drop of the system and also the proportion of the radial pressure drop arising from the bed. They also found good

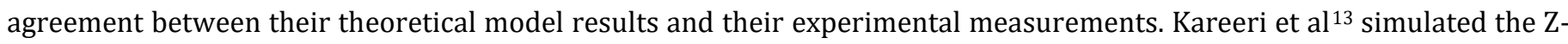
annular flow arrangement using computational fluid dynamics and found good agreement with both theoretical and experimental results obtained by Heggs et $\mathrm{al}^{6}$ and Heggs et $\mathrm{al}^{3}$.

In this present study, the theoretical Heggs et $\mathrm{al}^{6} \mathrm{Z}$-annular flow arrangement is used to experimentally investigate its influence on the enhancement of adsorption in a solid desiccant packed bed dehumidification system. Here, the experimental performance of a fully packed bed randomly filled with solid desiccants for dehumidification purposes is compared to the performance of annulus packed beds designed with this Z-annular flow configuration.

\section{Materials and Methods}

\subsection{Physical Model Description}

Figure $1 \mathrm{a}$ and $1 \mathrm{~b}$, shows 2D geometries of the fully packed bed and the annulus systems comprising of uniform copper cylinder with solid desiccant packing. Inlet moist air flows through the packed solid desiccants at Temperature $\mathrm{T}_{\text {in }}$ moisture content $\omega_{\text {in, velocity }} V_{\text {in, }}$ and pressure $P_{\text {in }}$ and exits dehumidified at the outlet at Temperature $T_{\text {out, }}$ moisture content $\omega_{\text {out, }}$ velocity $V_{\text {out, }}$ and pressure $P_{\text {out. }}$ The length of each vessel is designated $L$ and the diameter, $\mathrm{D}$ with the inner and outer annulus diameters designated $D_{i}$ and $D_{0}$ respectively. As determined from literature, the annulus packing arrangement enhances fluid-solid interaction and also reduces pressure drop across the bed ${ }^{3,7}$. Three mass transfer zones, equidistance from each other, referred to as MTZ1, MTZ2 and MTZ3 respectively are the designated probe points for the insertion of thermocouples (TCs). 


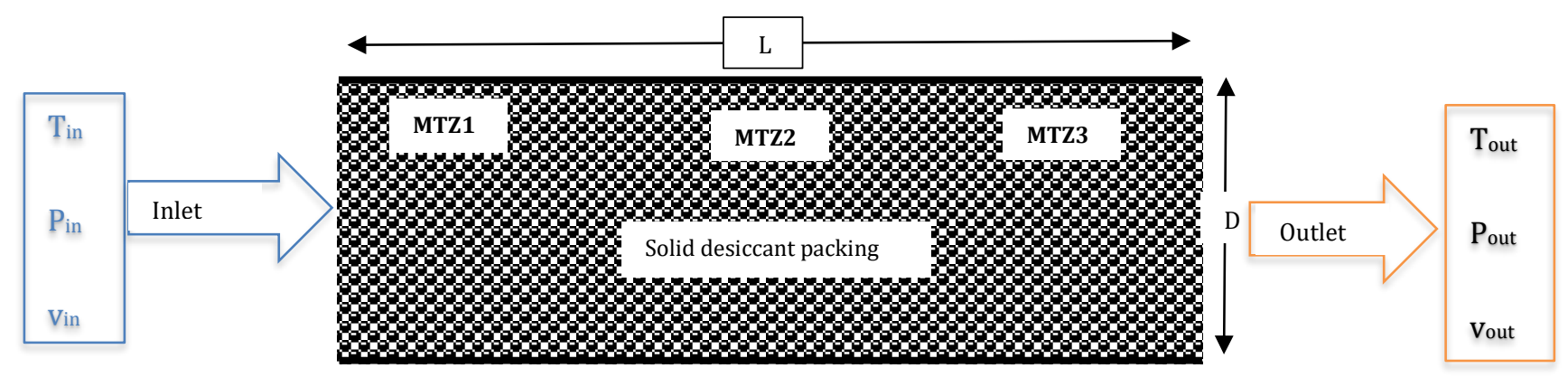

Figure 1a Schematic of the Fully Packed Bed Structure Showing Mass Transfer Zones

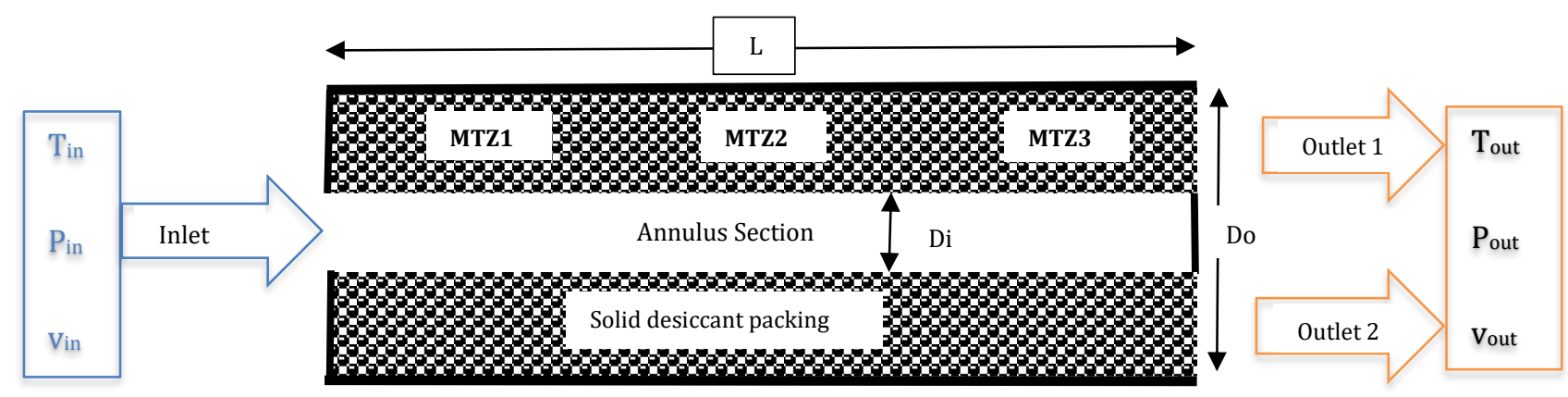

Figure $1 b$ Schematic of the Annulus Packed Bed Configuration Showing Mass Transfer Zones

\subsection{Solid Desiccant Selection}

Silica gel/silicon dioxide $\left(\mathrm{SiO}_{2}\right)$ was chosen as the suitable adsorbent for the adsorption of water vapour in this investigation. Several studies have shown silica gels is suitable for physical adsorption in dehumidification and cooling applications. For instance, Pramuang and Exell ${ }^{14}$ found that silica gels are very common adsorbent available commercially and operate very well between relative humidity values of $50 \%$ and $80 \%$ making them suitable for dehumidification processes. Chang et $\mathrm{al}^{15}$ also found that silica gels are utilized for dehumidification processes in industrial and residential applications due to their wide pore surface area, good moisture adsorption capacity and lower regeneration temperature. An investigation carried out by Sun and Besant ${ }^{16}$ also shows that silica gel has very high moisture adsorption capacity and may adsorb moisture up to one-third of its dry mass. Yang ${ }^{17}$ also found silica gel to be the most widely used desiccant due its large capacity for water $(\sim 40 \%$ by weight $)$ and ease in regeneration at approximately $150^{\circ} \mathrm{C}$, compared with $350^{\circ} \mathrm{C}$ for regenerating zeolites another common adsorbent. Ulku and Mobedi ${ }^{18}$ obtained the highest cooling coefficient of performance for cooling systems using silica gel-water working pair than other systems using other common adsorbentadsorbate working pairs.

\subsection{Packed Bed System Design and Fabrication}

The packed bed shown in Figure 2a is a simple cylindrical vessel with two caps at both ends for the inlet and outlet. Inside the vessel are copper meshes (See Figure 2b) designed to hold the silica gel particles in place near the inlet and outlet for the fully packed bed and at the outlet for the annulus packed bed. Table 1 shows the packed bed dimensions. On the main vessel are the three thermocouple (TC) probes for temperature measurement in the mass transfer zones MTZ 1, MTZ 2 and MTZ 3 within the solid desiccant packing (see Figure 2c for schematic of the packed bed). On the inlet and outlet sections are probe points for the measurement of temperature, velocity, pressure and relative humidity. 


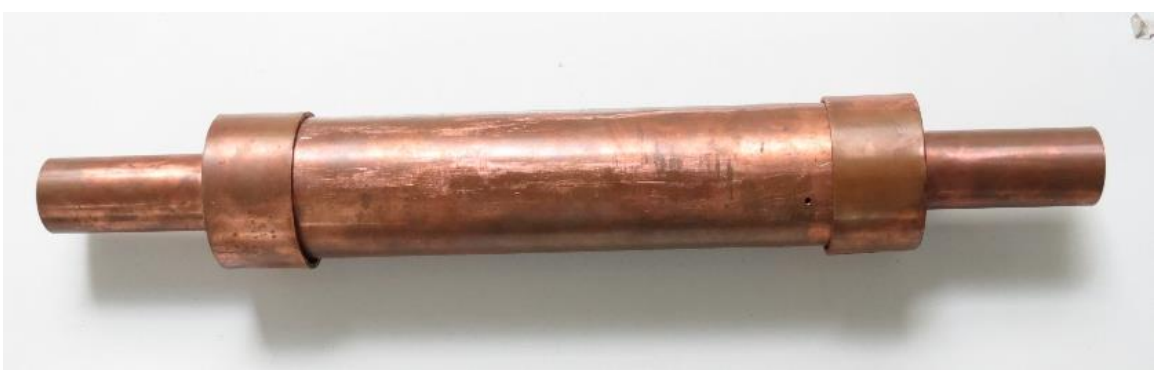

Figure 2a. Copper Packed Bed Vessel with Inlet and Outlet Caps
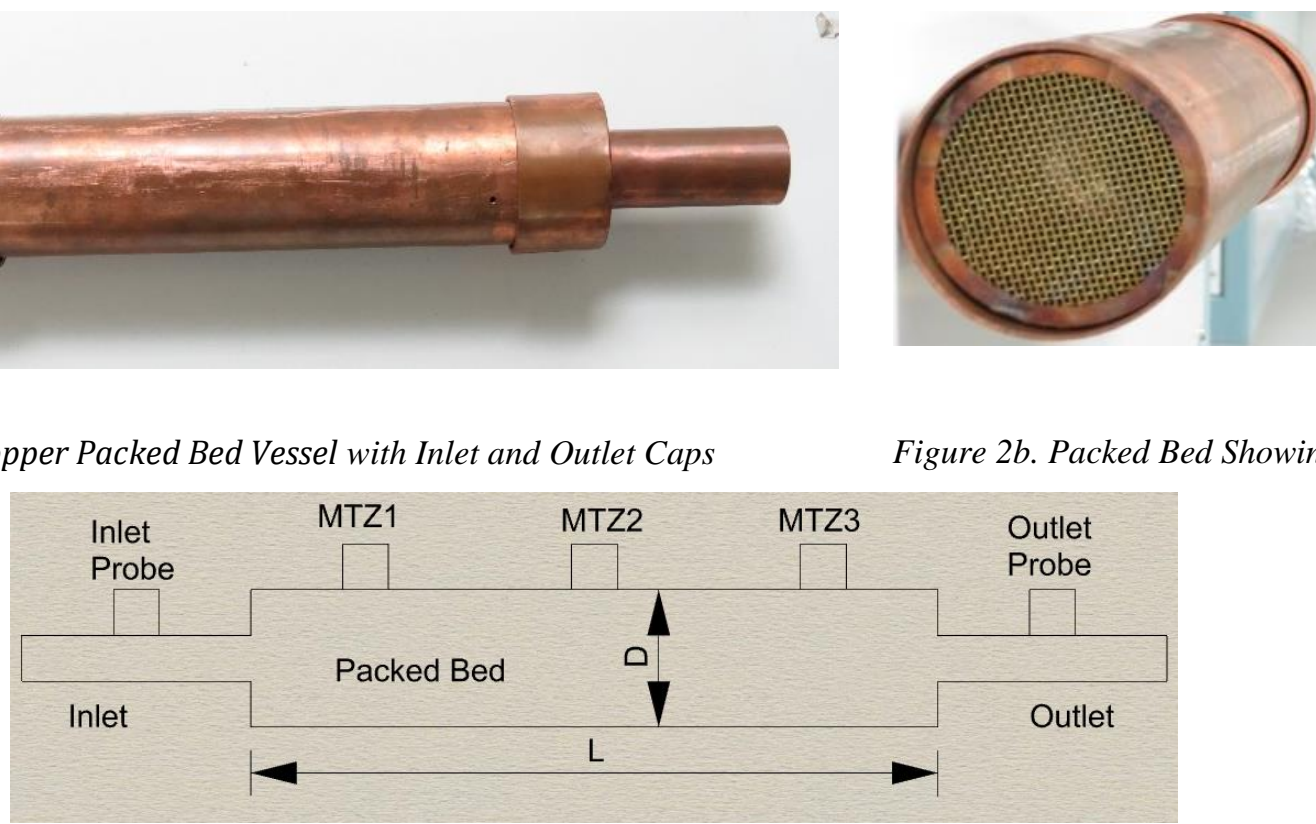

Figure 2c. Schematic Diagram of Packed Bed Vessel

\begin{tabular}{|l|l|l|l|}
\hline \multicolumn{4}{|c|}{ Table 1. Packed Bed Parameters } \\
\hline Section & Parameter & Dimensions & Units \\
\hline Moist Air Inlet & Length & 0.15 & $\mathrm{~m}$ \\
\hline Packed Bed Outlet & Diameter & 0.04 & $\mathrm{~m}$ \\
\hline Packed Bed Vessel Wall & Length & 0.15 & $\mathrm{~m}$ \\
\hline Packing Section & Diameter & 0.04 & $\mathrm{~m}$ \\
\hline & Thickness & $\sim 1$ & $\mathrm{~mm}$ \\
\hline Mesh Screen & Length & 0.3 & $\mathrm{~m}$ \\
\hline & Diameter & 0.08 & $\mathrm{~m}$ \\
\hline
\end{tabular}

The packed bed is made of copper of thickness $1 \mathrm{~mm}$ with the inlet and outlets designed as caps to fit on the main cylindrical vessel. The cylindrical vessel was fitted with two meshes close to the inlet and outlet to hold the silica gel particles in place in order to maintain the $30 \mathrm{~cm}$ packing length. Each mesh was held in place by four (4) small screws drilled through the walls of the bed. Inserts for the thermocouples were made from three small holes equally spaced apart in a straight line on the vessel. Two of these holes were $5 \mathrm{~cm}$ from the inlet and outlet respectively and one placed exactly on the $15 \mathrm{~cm}$ mark on the vessel.

The packed bed was first tested empty and then with packed silica gel particles in order to determine the empty bed and real velocities respectively. This was done because the local velocity distribution in the bed is crucial to the overall bed performance in terms of pressure drop, residence time distribution, heat and mass transfer coefficient ${ }^{19}$. For nonuniform flow distribution, there is less utilization of the adsorbent during adsorption and of desorption fluid during regeneration ${ }^{20}$. According to Lu and Zhao ${ }^{21}$ the empty bed and real velocities are the two velocities defined for a fluid flowing through a porous medium. In this study, the results for the inlet and outlet velocities of the empty packed bed vessel and when fully filled with spherical solid desiccant particles are presented in Tables 2. 
Table 2 Packed Bed Testing Results

\begin{tabular}{|l|l|l|}
\hline Packed Bed & Inlet Velocity, m/s & Average Outlet Velocity, m/s \\
\hline Empty Vessel & 2.48 & 1.81 \\
\hline Fully Packed Bed & 2.48 & 0.1 \\
\hline
\end{tabular}

The mean porosity for the packing was determined using two volumetric cylinders and a scale balance. An amount of dry silica gel particles was placed in one of the volumetric cylinders and the volume and weight determined. A known quantity of water was then added to the dry particles in the volumetric cylinder and the new mass and volume determined. The loose packing density and the particle density were then used to determine the loose packing porosity. Table 3 shows the data used to determine the bed porosity.

\begin{tabular}{|c|c|c|}
\hline \multicolumn{3}{|c|}{ Table 3 Loose Packing Porosity Determination Data } \\
\hline \multicolumn{3}{|c|}{ Silica Gel } \\
\hline Parameter & Value & Units \\
\hline Dry Mass & 39.62 & g \\
\hline Wet Mass & 66.38 & g \\
\hline Dry Volume & 50 & $\mathrm{ml}$ \\
\hline Wet Volume & 55 & $\mathrm{ml}$ \\
\hline Particle Volume & $55-27=28$ & $\mathrm{ml}$ \\
\hline Loose Bed Density & $39.62 / 50=0.7924$ & gcc \\
\hline Particle Density & $39.62 / 28=1.415$ & gcc \\
\hline Porosity $(\varepsilon)$ & $1-(0.7924 / 1.415)=0.44$ & - \\
\hline \multicolumn{3}{|c|}{ Water } \\
\hline Total Volume & 73 & $\mathrm{ml}$ \\
\hline Residual Volume & 46 & $\mathrm{ml}$ \\
\hline Volume on Silica Gel Particles & $73-46=27$ & $\mathrm{ml}$ \\
\hline
\end{tabular}

\subsection{Annulus Section Design and Fabrication}

Annulus packing arrangement is found to enhance fluid-solid interaction and also reduce pressure drop across the bed $^{5-7}$. For this experimental study, cylinderical mesh pipes were designed and fabricated so they can be placed centrally in the packed bed. This was to allow the silica gel particles to be packed around them to ensure the radial flow of moist air within the bed. The annulus structures were determined within the ranges obtained from literature ${ }^{4-8}$ and were of outer and inner diameter ratios $\left(\mathrm{D}_{\mathrm{o}} / \mathrm{D}_{\mathrm{i}}\right)$ of 2, 2.35 and 3.08 presented here as LAPB, MAPB and SAPB consistent with large, medium and small annulus packed beds respectively. Figure 3a-b shows the schematic diagram of the inlet and side view respectively of the annulus insert. 


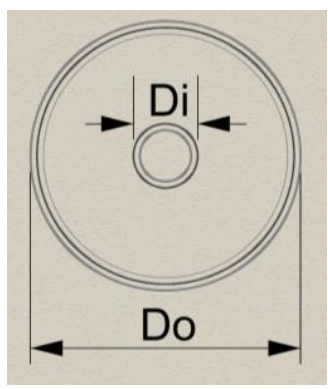

Figure 3a. Schematic of the Inlet of the Annulus Insert

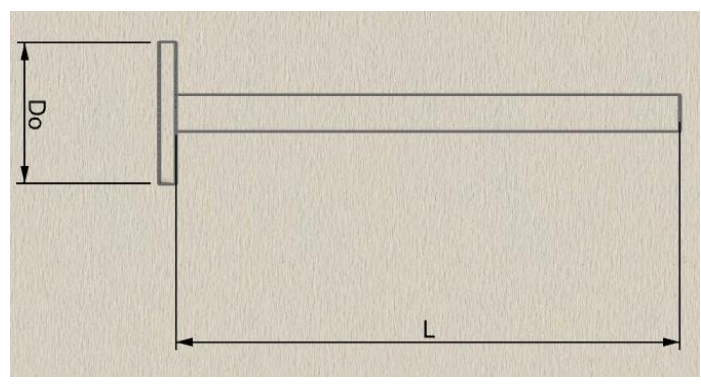

Figure 3b. Schematic of the Side of the Annulus Insert

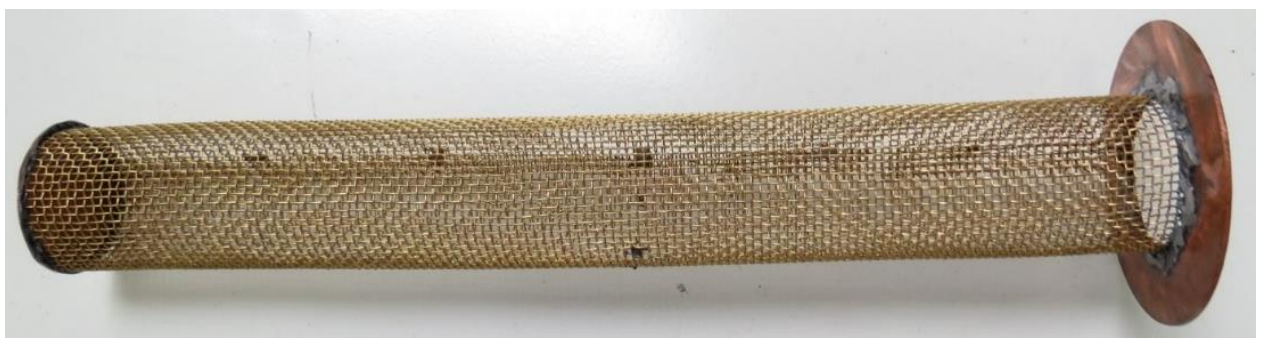

Figure 3c. Copper Annulus Insert

The annulus inserts are cylindrical mesh pipes made from copper mesh of size $0.08 \mathrm{~m}$ (See Figure 3c). They were capped at one end with a copper plate to ensure the distribution of the moist air is radial within the annulus section, a configuration consistent with the Heggs et $\mathrm{al}^{6}$ Z-annular flow arrangement. According to Heggs et al ${ }^{6}$ the basic assumption of the annular flow arrangement of a randomly packed bed is the uni-directionality of the radial flow. The typical dimensions of the packed bed vessel and its accessories are presented in Table 4.

\begin{tabular}{|l|l|l|l|}
\hline \multicolumn{4}{|c|}{ Table 4 Dimensions of the Fabricated Packed Bed and Its Accessories } \\
\hline Component & Length (cm) & Inner Diameter (cm) & Outer Diameter (cm) \\
\hline Packed Bed Vessel & 35 & 7.8 & 8 \\
\hline Large Annulus Section & 29 & 3.6 & 4 \\
\hline Medium Annulus Section & 28 & 3 & 3.4 \\
\hline Small Annulus Section & 28.4 & 2.3 & 2.6 \\
\hline Mesh Screen & - & 6.6 & 7.7 \\
\hline
\end{tabular}

\subsection{Experimental Methodology}

The experiments began with the preparation of the silica gel particles. This involved sieving to get the particles in the appropriate size range, determination of its mass before drying, drying at a maximum temperature of $140{ }^{\circ} \mathrm{C}$ in an electric oven for 4-5 hours and allowing the silica gel particles to cool. The cooled silica gel was then weighed again and finally packed in the vessel for adsorption. For the FPB, the silica gel particles were fully packed in a random manner and held in place by the mesh screens. For the annulus arrangement, the annulus inserts were placed centrally in the vessel and the silica gel particles randomly packed around them. For each experimental run, the packed bed was insulated with a $20 \mathrm{~mm}$ thick nitrile rubber thermal insulation material.

At the interior and the walls of the packed bed temperature measurement were taken using Omega k-type thermocouples. The thermocouples were inserted at the three points in the packed bed for the mass transfer zones MTZ1, MTZ2 and MTZ3 respectively as shown in Figures 1a and b. These thermocouples were connected to a Yokogawa MV2000 
Data Logger for temperature measurements typically within the packed beds and on their walls. The schematic of the setup is presented in Figure 4a whilst Figure 4b shows an image of the experimental set-up in the laboratory.

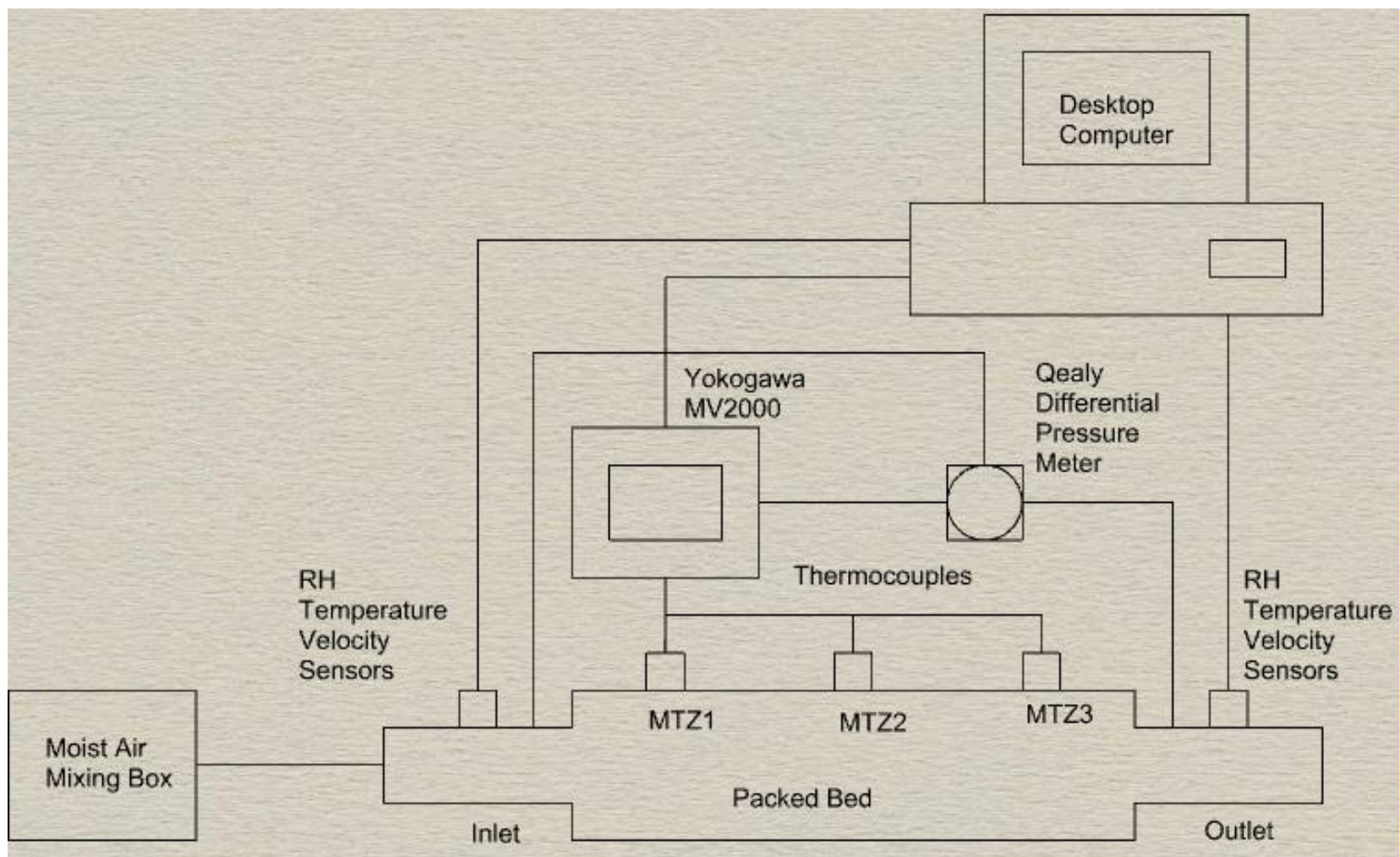

Figure 4 a Schematic of the Set Up of the Packed Bed for Adsorption

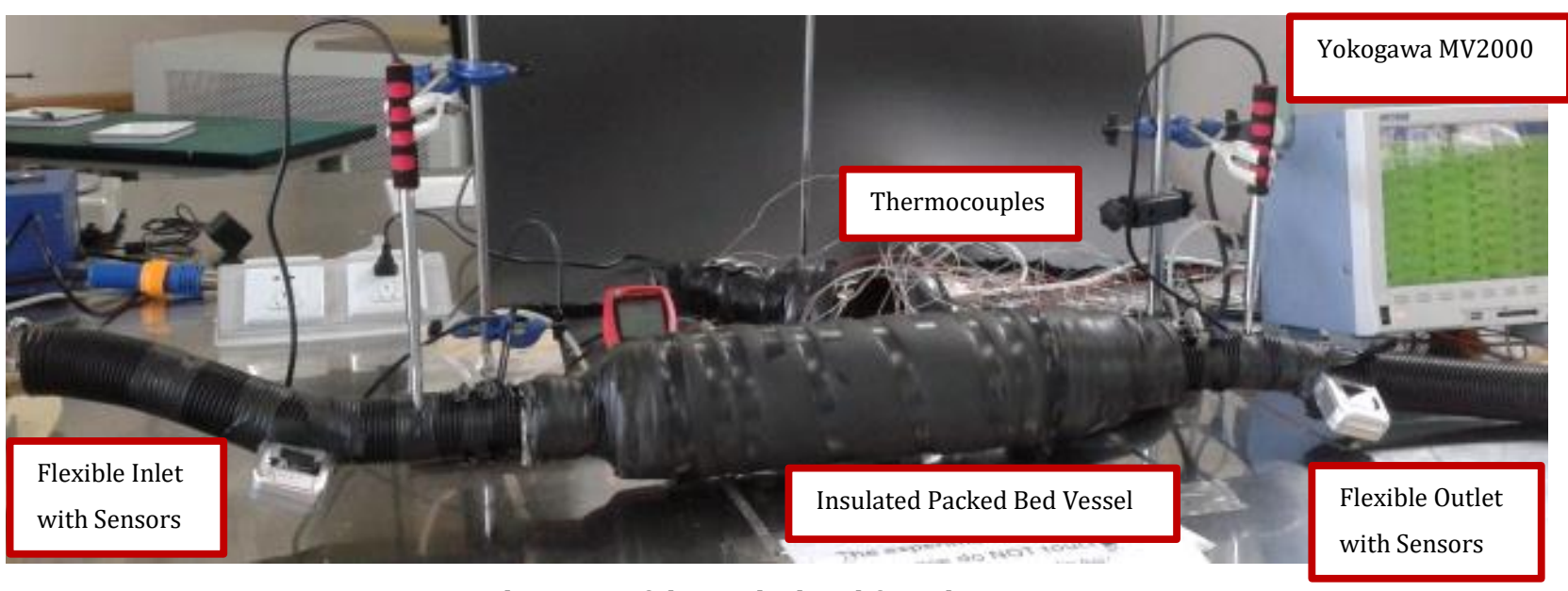

Figure $4 b$ Set Up of the Packed Bed for Adsorption

For inlet and outlet relative humidity and temperature measurements, AZ8829 data loggers were used. The AZ8829 data recorder measures and records the temperature and relative humidity and features an LCD display of the data. These data loggers were inserted in flexible pipes connecting the inlet and outlet of the adsorbing bed. The collected temperature and humidity data were then downloaded by connecting the AZ8829 data loggers to a personal computer (PC) via a docking station. Inlet and outlet velocities and corresponding air temperatures were measured using Sentry ST732 Hotwire Anemometers. The Sentry ST732 Hotwire Anemometer an air velocity, temperature of air, and non-contact infrared temperature measuring instrument combines hot wire and standard thermistor to deliver rapid and precise measurements even at low air velocity. This device also incorporating an LCD panel for data display, was connected directly to the PC for data download. 
For pressure measurements, probes were inserted in the inlet and outlet of the packed bed adsorber using the QEALY differential pressure meter. This pressure measurement device incorporates two compartments that connects the inlet and outlet pressure probes. An internal transducer connected via wires to the Yokogawa MV2000 Data Logger provided signals of the inlet and outlet pressures through electrical pulses. The pressure data obtained in Volts were then converted into Pascal's using a conversion factor.

The inlet of the packed bed was then connected to a mixing box where moist air was allowed to flow through into the respective bed configurations for adsorption. The data loggers were set to obtain data at 10 seconds interval to enable very small changes in the parameters being measured during the adsorption process to be observed.

\section{Results and Discussions}

The experiments were repeated several times and consistent results obtained are presented here. The results cover a comparison of the transient performances of the packed bed systems from the onset of adsorption to a relative steady state bed temperature for respective systems. Data was obtained at a sampling interval of 10.00s.

\subsection{Inlet Conditions}

The inlet air condition was controlled using an in-house uPvc fabricated moist air mixing box incorporating a domestic humidifier and a fan with a $300 \mathrm{~W}$ heating element. The inlet temperature and velocity data were obtained using the Sentry ST732 Hotwire Anemometer whilst the AZ8829 sensor and data logger was used to collect data on the relative humidity and temperature. There was slight variation in the inlet condition mainly due to the influence of the surrounding thermal environment and the inability of the individual humidifier, heater and fan integrated into the mixing box to provide a relatively constant output. Regardless, inlet conditions outside the CIBSE ${ }^{22}$ recommended indoor thermal comfort zone were maintained for all the packed bed inlets throughout the experiments. According to Hamed et al ${ }^{23}$, the inlet conditions are crucial as the air inlet humidity has a significant effect on the adsorption rate with vapour generation rate increasing gradually with increase in bed temperature and consequently the mass transfer potential.

Figures 5a-c shows the inlet condition of the packed beds. In Figure 5a, the inlet relative humidity obtained for each packed bed was converted to humidity ratio in $\mathrm{kg} / \mathrm{kg}$ of dry air to give an indication of the amount of moisture present. To determine the inlet moisture content, the saturated vapour pressure over water in $\mathrm{kPa}$ was determined using the inlet temperature and equation (1) obtained from CIBSE Guide $\mathrm{C}^{24}$.

$$
\log p_{g}=30.59051-8.2 \log (\theta+273.16)+2.4804 \times 10^{-3}(\theta+273.16)-[3142.31 /(\theta+273.16)]
$$

The saturated vapour pressure over water was then used to determine the moisture content in $\mathrm{kg} / \mathrm{kg}$ of dry air of the saturated moist air using equation (2) as presented in CIBSE Guide $\mathrm{C}^{24}$ and Jones ${ }^{25}$. Here, the dimensionless enhancement factor, $f_{s}$, value of approximately 1.004 at a barometric pressure of $101.325 \mathrm{kPa}$ and a temperature of $0^{\circ} \mathrm{C}$ was used 25 .

$$
\omega_{s}=\frac{0.62197 f_{s} p_{g}}{101.325-f_{s} p_{g}}
$$

The moisture content of the saturated moist air along with the relative humidity obtained from the AZ8829 sensor and data logger was then applied to equation (3) to determine the moisture content of unsaturated moist air, $\mathrm{kg} / \mathrm{kg}$ of dry air as outlined in CIBSE Guide $\mathrm{C}^{24}$ and Jones ${ }^{25}$. 


$$
\omega=\frac{R H \times \omega_{s}}{100}
$$

The plot in Figure 5a shows unsteady inlet humidity ratio profiles for the packed beds typically ranging between 0.0087 to $0.011 \mathrm{~kg} / \mathrm{kg}$. The variations observed with the inlet conditions were mainly due to the influence of the surrounding thermal environment and the inability for the individual humidifier, heater and fan integrated into the mixing box to provide a relatively constant output although the heater temperature and the moisture settings from the humidifier were set at constant values throughout the experiment. The ambient temperature condition in itself varied only marginally over time between experiments.

For the annulus packed beds, the moist air went through the annulus sections before being impeded by the end copper plate due to the Heggs et $\mathrm{l}^{6}$ "Z" arrangement. As more moist air flowed through the annular sections, the end plate caused reversed flow which increased the concentration of moisture at the inlet hence the initial dip and subsequent increase in the humidity ratios observed at the inlet of the annulus packed beds in Figure 5a. The same condition caused relative instabilities in the moisture concentration at the inlet overtime for the annulus packed beds. For the FPB, it also encountered an initial dip and subsequent increase though, that was mainly due to the flow being impeded by the slilca gel packing adjacent to the inlet. As the moist air encountered impediments in its path, the concentration of moisture increased as a result of moisture build up which overtime made its way through the porous packing for adsorption to take place.

In Figure 5b, the profiles for the inlet temperature conditions are presented. The heat supplied to the air to increase it temperature was generated by the convective heater at the back of the mixing box which was set to a constant heat input value. It would be recalled that the moisture added to air was at ambient temperature hence the increase in moisture content occurred at relatively constant wet bulb temperature as no enthalpy was added from the humidifier side. The inlet velocities on the other hand varied significantly with the packed bed configuration type as shown in Figure 5c. Although for the empty bed the fan was able to generate a velocity of about $2.48 \mathrm{~m} / \mathrm{s}$, the respective packing reduced the inlet velocities significantly. For the annulus packed beds, inlet velocity increased with increasing annulus diameter. Here, the flow through the annulus section was impeded by the end plate causing a reversal of the moist airflow through the bed. The packed bed with the relatively larger annulus dimension accommodated more moist air allowing radial flow for adsorption to take place with only a small amount of the flow reversing from being impeded by the end plate. With a comparatively smaller annulus diameter, the influence of the air flow reversal was significant hence limiting the inlet flow velocity. For the FPB, the silica gel packing near the inlet impeded the flow which subsequently influenced the inlet velocity. 


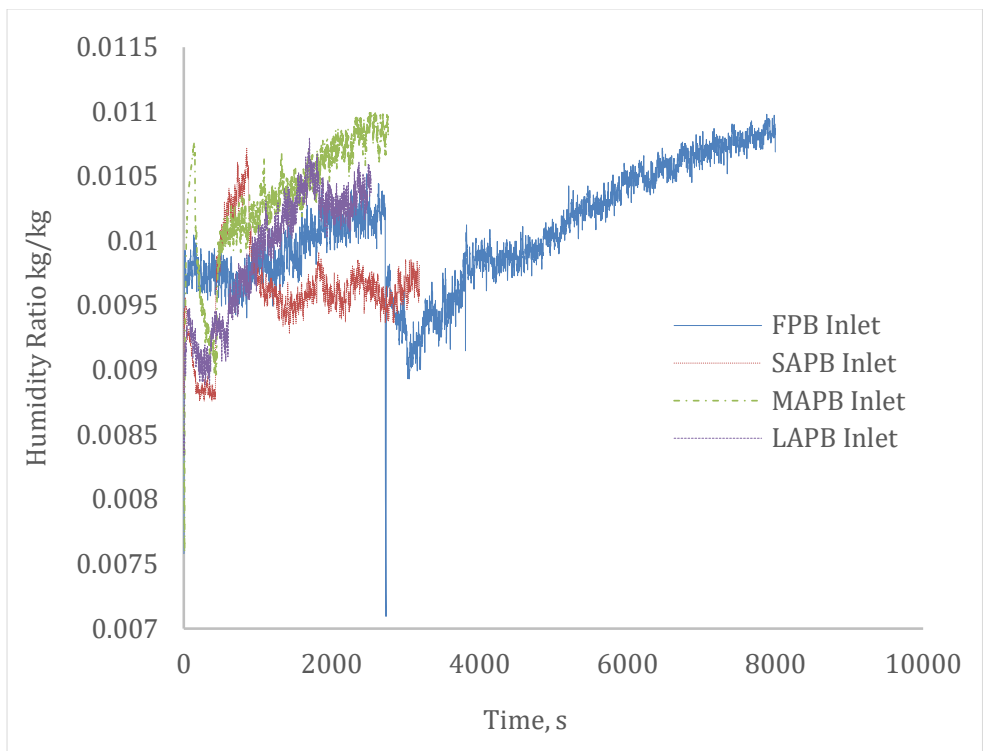

a) Inlet Humidity Ratio

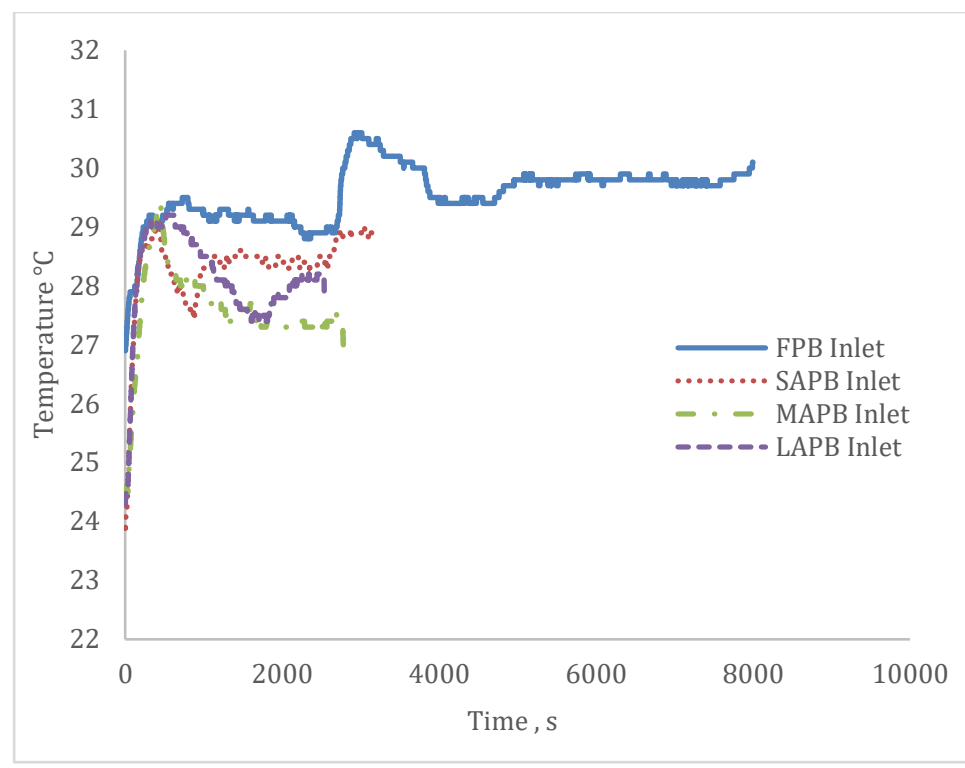

b) Inlet Temperature

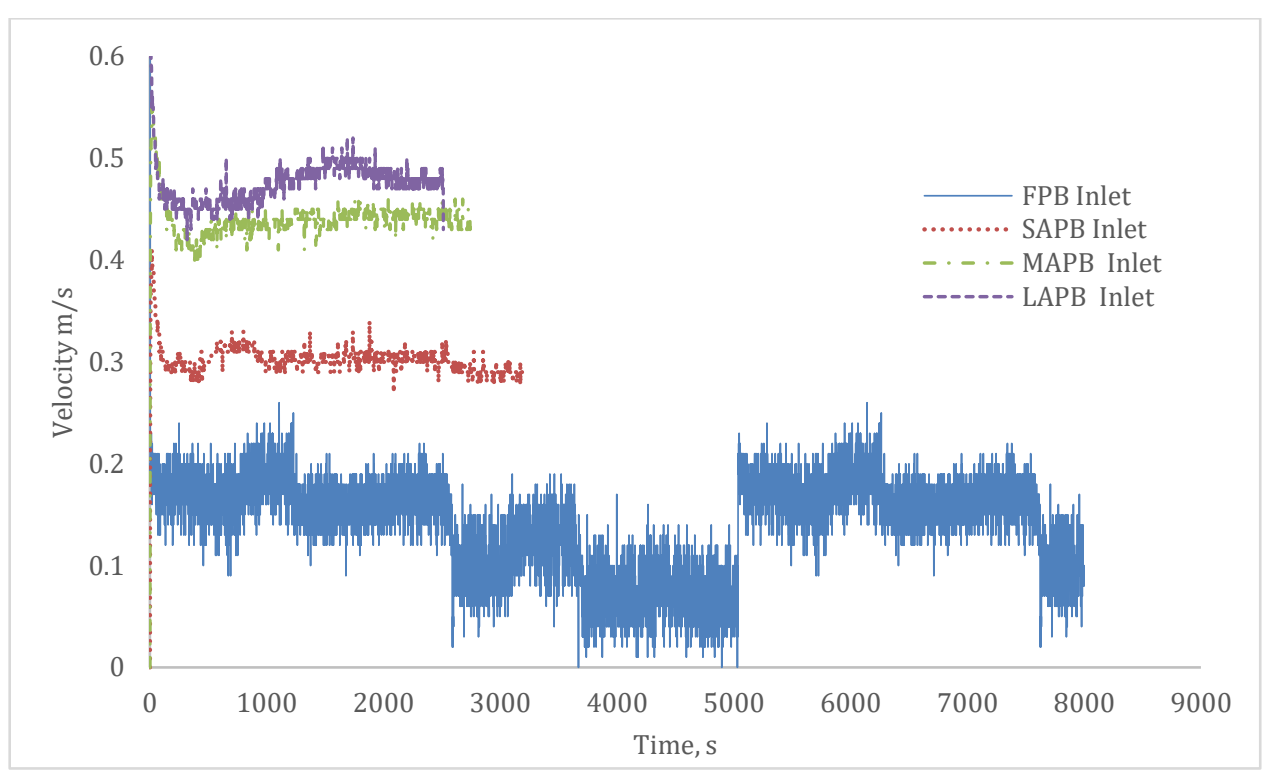

c) Inlet Velocity

Figure 5 Packed Bed Inlet Conditions

Averages of the inlet moist air conditions for the packed beds presented in Table 5 shows that the inlet velocity decreased with increasing mass of the silica gel particles. For the moisture content, the average values show the conditions at the inlet were similar for all packed beds. For the inlet temperature, there was slight variation in values between the various packed bed inlets. The moist air properties shows that the inlet conditions were beyond the recommended thermal comfort conditions as outlined in the CIBSE Guide $\mathrm{A}^{22}$. For instance the enthalpy and relative humidity of the moist air at each inlet were relatively higher than the recommended comfort levels hence at those conditions the removal of the latent heat is vital. The enthalpy was determined in terms of its specific heat ${ }^{26}$ for an ideal condition and expressed accordingly in equation (4).

$h=c_{p} T$ 
Table 5 Packed Bed Average Inlet Moist Air Properties and Condition

\begin{tabular}{|c|c|c|c|c|c|}
\hline Packed Bed Type & FPB & LAPB & MAPB & SAPB & Comments \\
\hline Temperature, ${ }^{\circ} \mathrm{C}$ & 29.56 & 28.13 & 27.60 & 28.34 & \multirow[t]{3}{*}{ Directly obtained from sensors } \\
\hline Velocity, m/s & 0.14 & 0.48 & 0.44 & 0.30 & \\
\hline Relative Humidity \% & 86.63 & 88.50 & 93.48 & 85.32 & \\
\hline Density, kg/m³ & 1.1311 & 1.1340 & 1.1355 & 1.1364 & \multirow{4}{*}{$\begin{array}{l}\text { Enthalpy and Specific Volume } \\
\text { interpolated linearly using data } \\
\text { from CIBSE Guide } C^{24} \\
c_{p} \text { calculated from equation (7) }\end{array}$} \\
\hline Enthalpy, kJ/kg & 82.29 & 82.54 & 82.52 & 79.08 & \\
\hline Specific Heat at Constant Pressure, $c_{\mathrm{pw}}, \mathrm{kJ} / \mathrm{kg} \cdot \mathrm{K}$ & 2.8326 & 2.9342 & 2.9877 & 2.8013 & \\
\hline Specific Volume, $\mathbf{m}^{3} / \mathbf{k g}_{\mathrm{da}}$ & 0.8841 & 0.8818 & 0.8807 & 0.8710 & \\
\hline $\begin{array}{l}\text { Moisture content of unsaturated moist air } \\
\text { (kg/kg of dry air) }\end{array}$ & 0.01008 & 0.00993 & 0.01034 & 0.00962 & \multirow{3}{*}{$\begin{array}{l}\text { Moisture content values and } \\
\text { saturated vapour determined } \\
\text { from equations } 1-3 \text { obtained } \\
\text { from CIBSE Guide C }{ }^{24} \text { and } \\
\text { Jones }^{25}\end{array}$} \\
\hline $\begin{array}{l}\text { Moisture content of saturated moist air }(\mathrm{kg} / \mathrm{kg} \\
\text { of dry air) }\end{array}$ & 0.8841 & 0.8818 & 0.8807 & 0.8710 & \\
\hline Saturated vapour pressure over water $(\mathrm{kPa})$ & 1.85 & 0.48 & 0.44 & 0.30 & \\
\hline
\end{tabular}

\subsection{Heat Transfer in the Packed Beds}

The temperature profiles in the packed beds presented in Figures 6a-d shows the packed bed temperatures in the mass transfer zones obtained using Omega K-type thermocouples. Physical adsorption fundamentally involves simultaneous heat and mass transfer coupled with the equilibrium properties of a packing of solid desiccant of which thermal energy is generated as a consequence of the mass transfer ${ }^{27-28}$. In typical solid desiccant packed beds, air flowing over the bed loses part of its moisture content to the particles through transient heat and moisture transfer process which significantly determines the packed bed's adsorption performance ${ }^{29-30}$. In this study, temperature measurements were obtained from the mass transfer zones signifying heat released as a result of the moisture transferred to the silica gel. The ambient temperature measurements in Figures 6a-d provide reference temperatures reflecting the condition of the surrounding environment and the baseline to the temperature increase resulting from the adsorption process. According to Awad et al ${ }^{5}$ higher rate of adsorption during the first few minutes, results in the heat generation rate rapidly increasing the bed temperature. The temperature reaches a maximum value, and then decreases gradually as the flowing air extracts heat from the bed and the adsorption rate also decreases. For a conventional fully packed bed, the water vapour is initially adsorbed at the inlet containing active solid desiccants resulting in the adsorbent nearest the inlet becoming saturated with water vapour at the condition of the feed gas, with the zone of rapid water adsorption moving inwards and ultimately progressing through the entire bed ${ }^{1}$.

For the FPB in Figure 6a, the temperature of MTZ1 rose significantly due to the moist air interacting with the silica gel particles and releasing the heat of adsorption. In this zone a maximum temperature of about $57.1^{\circ} \mathrm{C}$ was recorded. The zone of mass transfer then increased with time in the direction of the moist airflow and this was observed with the subsequent increase in temperatures of MTZ2 and MTZ3 respectively, a phenomenon consistent with findings by Nic An tSaoir et $\mathrm{al}^{31}$. Here the maximum achieved for MTZ2 was about $45^{\circ} \mathrm{C}$ and about $40^{\circ} \mathrm{C}$ for $\mathrm{MTZ3}$ before they both declined to relative steady state temperatures. The trends observed were also consistent with experimental measurements of water vapour on silica gel particles carried out by Hamed et $\mathrm{al}^{23}$. They found that the rate of adsorption of water vapour from air stream takes its maximum value at the beginning of the adsorption cycle and decreases to a nearly steady-state value. The 
decline in the bed temperature in MTZ1 was as a result of the particles in the path of the moist air approaching saturation hence not releasing further adsorption heat on fluid-solid contact.

For the annulus packed bed configurations shown in Figures $6 \mathrm{~b}-\mathrm{d}$, a significant rise in temperature at the commencement of the adsorption process was also observed. However due to the Heggs et al ${ }^{6} \mathrm{Z}$-annular flow arrangement, the temperature increase in the zone of mass transfer was counter flow to the inlet airflow direction. This was due to the capped end of the annulus insert impeding the airflow and as more air flowed through the annulus section, turbulent ed dies were created around the capped end forcing more air to flow radially starting from the end of the bed where the turbulent eddies begun. This phenomenon increased the adsorption rate hence the significant rise in the bed temperature in MTZ3 for all three annulus packed bed configurations due to the heat of adsorption released.

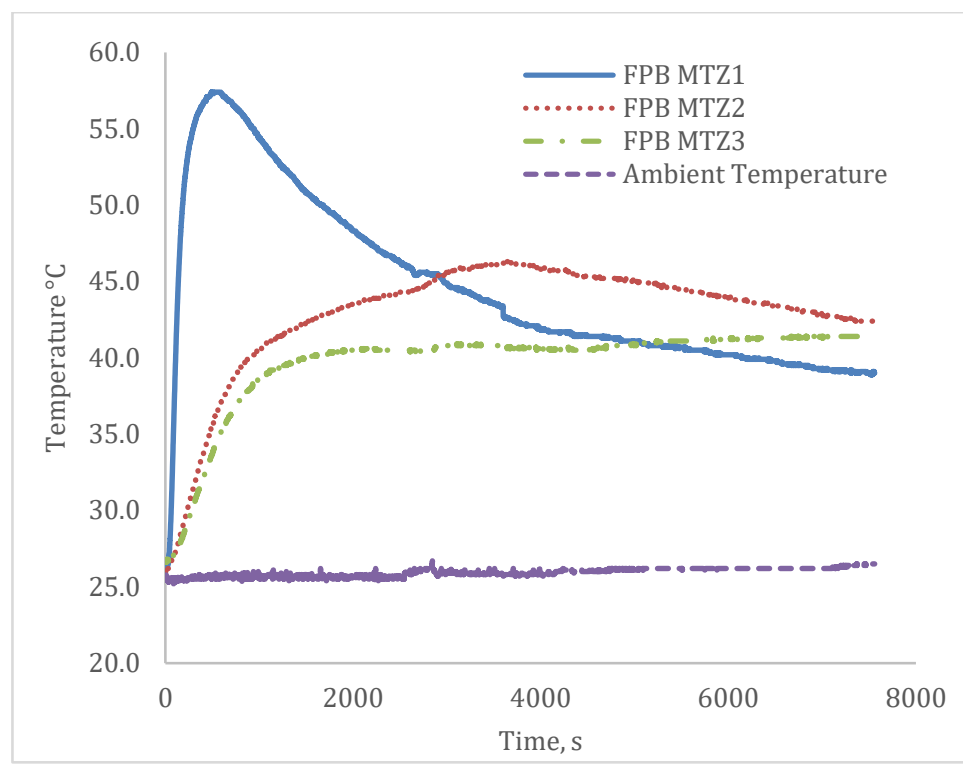

a) $F P B$

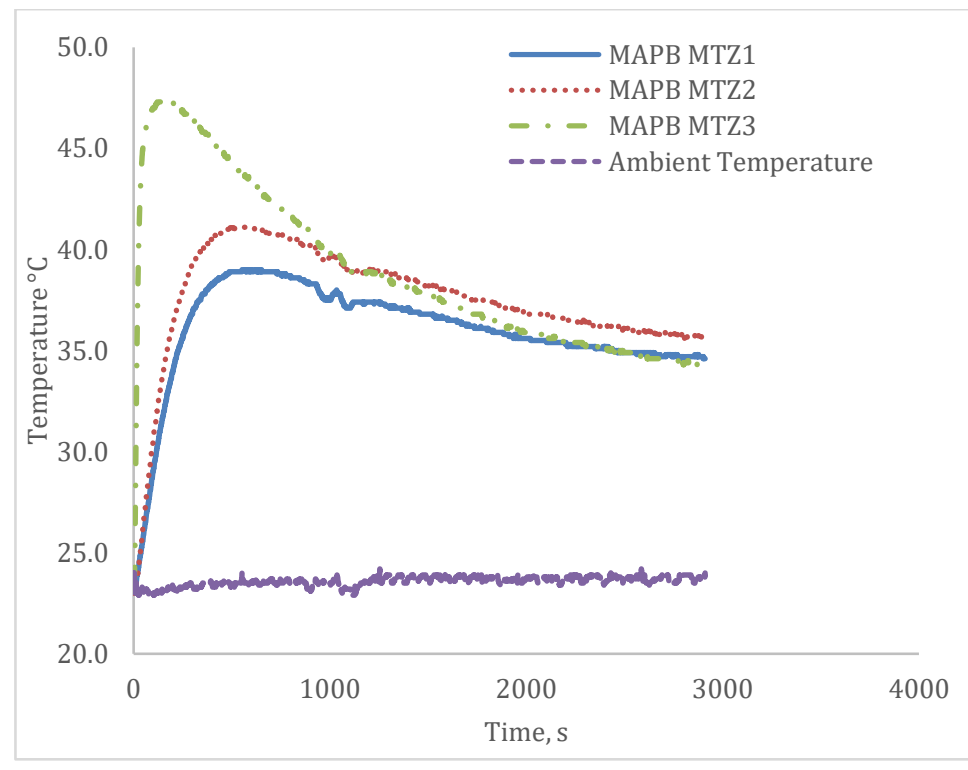

c) $M A P B$

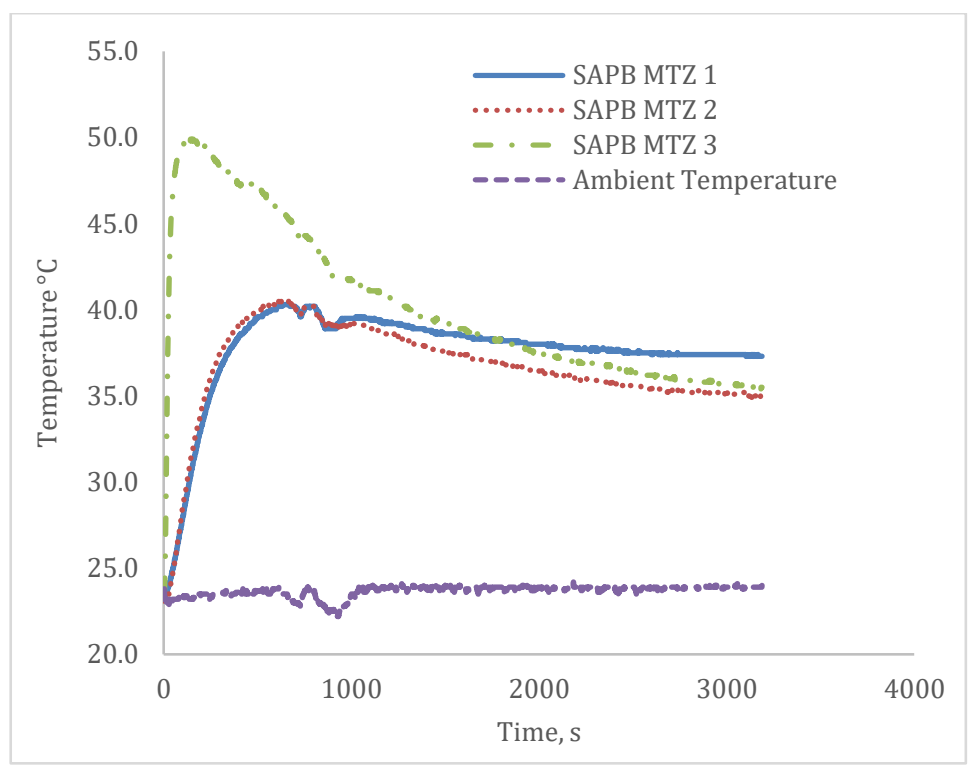

b) $S A P B$

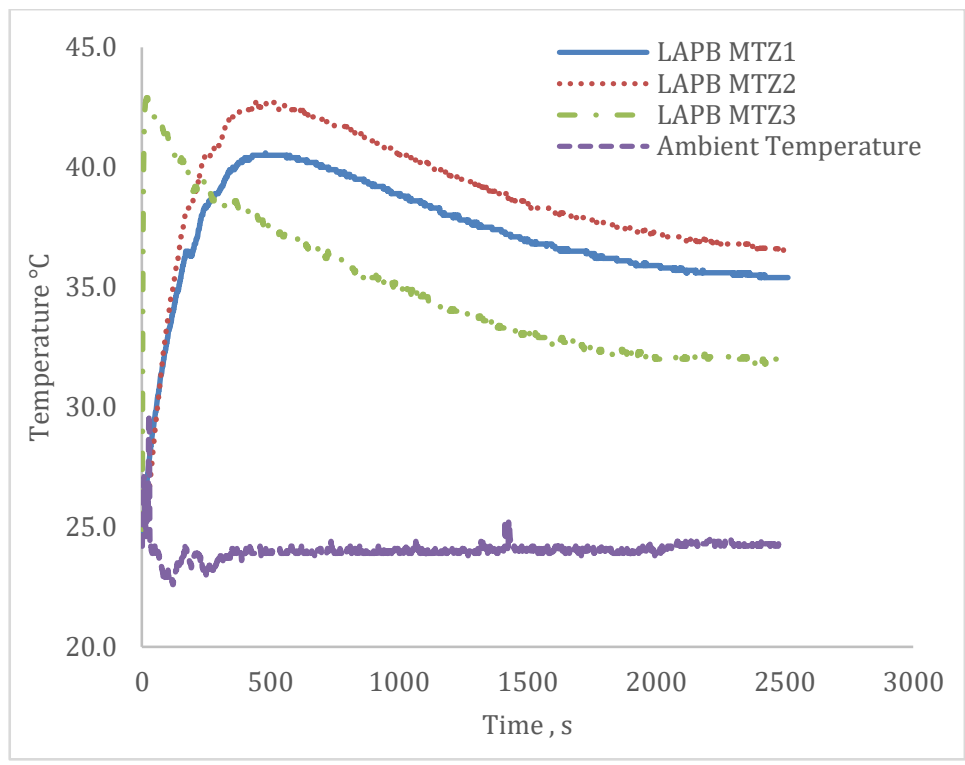

d) $L A P B$

Figure 6 Packed Bed Temperature

Comparing the annulus packed bed configurations, the temperature increase in respective MTZ3 occurred with respect to the total mass of silica gel particles available for adsorption in that zone for each configuration. It must be said with caution that, the more silica gel particles were available for the adsorption process, the likelihood a higher amount of 
heat of adsorption would be released given that effective fluid-solid contact occurred. In this present study, the Heggs et al ${ }^{6}$ Z-annular flow configuration fundamentally facilitated the radial distribution of moist airflow within the bed ensuring an increase in participation of the silica gel particles in the adsorption process. The sharp decline of the temperature in MTZ3 also showed the rate at which saturation in those zones were achieved. For the LAPB in Figure 6d, the decline in temperature was sharp and fell significantly below the temperatures of its MTZ2 and MTZ1 in that order. In all the mass transfer zones, the trend was an initial sharp rise and a relatively steady decline to a relative steady state bed temperature.

Average temperature values determined shows a general increase in overall bed temperature with increasing bed mass (see in Figure 7). The trend shows an initial increase in bed temperature before a steady state condition is reached for all packed beds. For the annulus packed beds, there was slight variation in the average bed temperature increasing with decreasing annulus section. From the plots, it was observed that the annulus packed bed configurations effectively had a lower overall bed temperature. However, it is not apparent at this stage in the study whether a similar reduction in bed temperature would be achieved for fully packed beds with the same mass as the annulus ones presented here. Average temperatures of $42.4^{\circ} \mathrm{C}, 36.93^{\circ} \mathrm{C}, 37.51^{\circ} \mathrm{C}$ and $38.18^{\circ} \mathrm{C}$ were respectively obtained for the FPB, LAPB, MAPB and SAPB configurations. This reflected a temperature reduction of about $5.47^{\circ} \mathrm{C}, 4.89^{\circ} \mathrm{C}$ and $4.22^{\circ} \mathrm{C}$ between the $\mathrm{FPB}$ and the $\mathrm{LAPB}$, MAPB and SAPB configurations respectively.

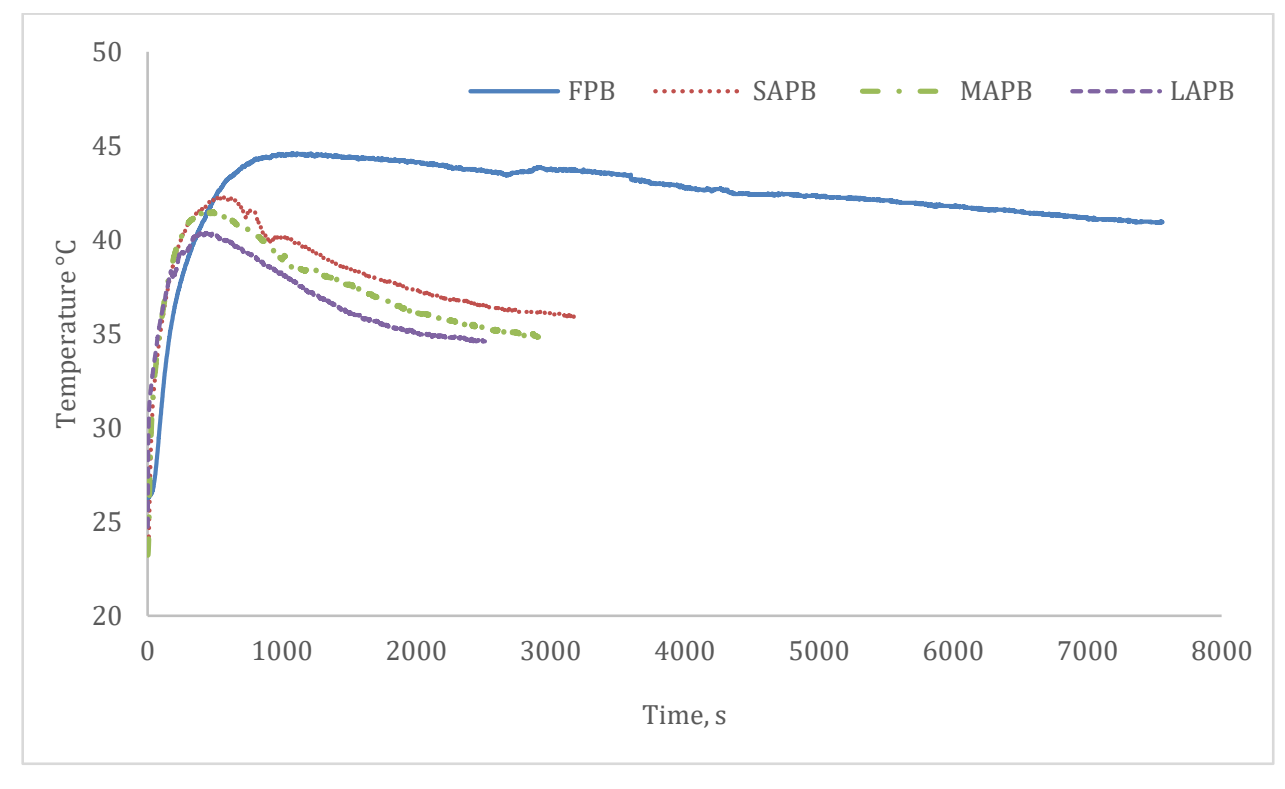

Figure 7 Average Packed Bed Temperatures

The heat fluxes from the packed bed and its annulus variations were determined using equation (5) from Kabeel ${ }^{32}$, the average bed temperatures and data from Tables 3,4,5,6 \& 7. Table 6 shows material density of the silica gel and its specific heat capacity determined from experimental pycnometer measurements and digital scanning calorimetry (DSC) measurement respectively. Table 7 on the other hand shows the data for the determination of the bulk density of each packed bed configuration.

$\rho_{g} c_{p} \mu_{o}\left(T_{g i}-T_{p}\right) d t=\rho_{s} c_{p s}(1-\varepsilon) L d T_{p}+W \rho_{s} c_{p w}(1-\varepsilon) d T_{p}$

Table 6 Experimentally Determined Material Properties of Silica Gel

\begin{tabular}{|l|l|l|l|}
\hline Parameter & Value & Units & Comments \\
\hline Density of Silica Gel & 2320.2 & $\mathrm{~kg} / \mathrm{m}^{3}$ & Experimentally determined \\
\hline Specific Heat Capacity of Silica Gel, $c_{p s}$ & 1047.243 & $\mathrm{~J} / \mathrm{kg}$ & Experimental Average \\
\hline
\end{tabular}




\begin{tabular}{|l|r|r|r|}
\hline \multicolumn{4}{|c|}{ Table 7 Packed Volume and Silica Gel Bulk Density } \\
\hline Packed Bed & Mass of Silica Gel Weight, g & Packed Bed Volume, m & Bulk Density kg/m $^{3}$ \\
\hline FPB & 1099.00 & 0.00143 & 768.53 \\
\hline LAPB & 881.71 & 0.00113 & 780.27 \\
\hline MAPB & 903.18 & 0.00122 & 740.31 \\
\hline SAPB & 987.90 & 0.00131 & 754.12 \\
\hline
\end{tabular}

Figure 8 illustrates the profiles of the heat released from the packed beds determined from equation (5). The general trend reveals an initial higher heat output from each packed bed configuration before a steady decline. It is apparent that average heat flux density for the SAPB peaked at a higher value than the other packed bed variations. The explanation here may be that the SAPB has relatively more mass of silica gel and its annulus structure enhanced the fluid solid contact which generated the heat of adsorption. Contrary to the SAPB, the FPB with the most silica gel mass amongst the packed bed variations appears to have comparatively reduced average heat output which can be deduced to be related to the possibility of poor distribution of moist airflow within the bed. This situation may be as a result of the mal-distribution of the moist air flow within this bed configuration type as opposed to the radial distribution of the moist airflow in the annulus bed type. Over the course of the experiment, the average heat flux from the FPB, SAPB, MAPB and LAPB were respectively $2040 \mathrm{~kW} / \mathrm{m}^{2}$, $2519 \mathrm{~kW} / \mathrm{m}^{2}, 1684 \mathrm{~kW} / \mathrm{m}^{2}$ and $1668 \mathrm{~kW} / \mathrm{m}^{2}$. For the annulus bed types the heat output increased with decreasing annulus diameter.

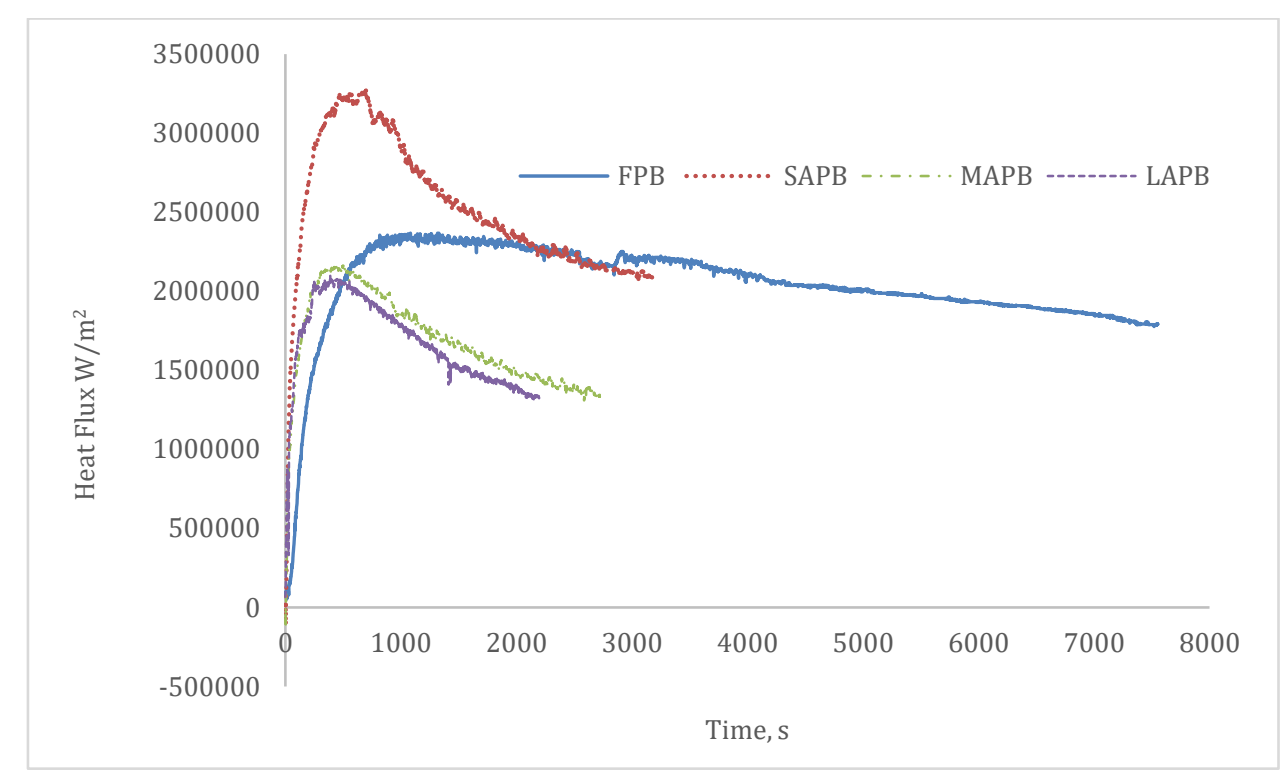

Figure 8 Average Heat Output from Packed beds

In each mass transfer zone, two thermocouples were inserted at varied lengths to as much as possible capture the temperature within the zone. Although efforts were made to ensure the thermocouples were within the silica gel particles, it was difficult to ensure all lengths of the sensor in the packing were the same. On the basis of possible mal-distribution of flow within the packed bed, this could be a potential source of error although several tests carried out gave confidence in the results presented. The ability of the thermocouples to also capture the slight variations in temperature was dependent on its type and this potentially affected the precision and accuracy of the results. The Yokogawa MV2000 that connected the thermocouples and the computer for data collection was able to log data at a minimum interval of 5.00s. On testing data 
sampling between 5.00s and 10.00s, it was found that the results were the same hence not much oscillations were captured with the minimum possible sampling interval.

\subsection{Moisture Transfer in the Packed Beds}

The mass of the silica gel particles was determined before and after adsorption using a scale balance, see Table 8. The conditioning of the silica gel before adsorption involved weighing, drying, cooling under ambient conditions whilst in an air tight container to prevent moisture adsorption and then weighing again. After adsorption, the silica gel particles were weighed again and the difference in mass before and after adsorption determined. Over the period of study, the FPB adsorbed about $164 \mathrm{~g}$ of moisture, the SAPB about $104.07 \mathrm{~g}$ of moisture, the MAPB adsorbed about $114.25 \mathrm{~g}$ of moisture and the LAPB about 50.94g of moisture as shown in Table 8. It is important to note that these measurements were obtained after the respective packed beds reached a relative steady state temperature condition and their outlet relative humidity was beyond the CIBSE $^{22}$ recommended indoor relative humidity for thermal comfort. As presented in Table 8, the time when the packed beds reached steady state temperature increased with increasing mass of silica gel particles. However, it was also observed that over the relatively shorter period that the MAPB reached steady state, it adsorbed a somewhat a greater amount of moisture than the SAPB which has a larger silica gel mass and took longer to reach its steady state condition. This could be as a result of the fact that with a comparatively smaller annulus dimension than the MAPB, the characteristics of the SAPB packing structure was similar to that of a fully packed bed hence a similar moist air flow path for adsorption. A snapshot of the equivalent amount of moisture adsorbed after 2000s for all packed beds presented in Table 8 shows that the MAPB outperformed all configurations within this time. The MAPB configuration benefits from a relatively smaller annulus dimension and relatively larger silica gel mass compared to that of the LAPB. The relatively short period the LAPB attained steady state condition also suggests enhanced fluid-solid contact hence saturation within that short period. Although overall the mass of silica gel present in the FPB was greater than the annulus type beds, it appears that the radial flow of moist air in the annulus configurations increased the adsorption capacity of those beds. It can be inferred that the FPB configuration did not enhance the fluid-solid contact required for adsorption hence over the same period for all packed beds, the amount of moisture adsorbed was comparatively small.

\begin{tabular}{|c|c|c|c|c|}
\hline \multicolumn{5}{|c|}{ Table 8 Mass of Moisture Adsorbed by Silica Gel } \\
\hline Packed Bed Type & FPB & LAPB & MAPB & SAPB \\
\hline Silica Gel Mass Before Oven Drying, g & 1190.00 & 996.21 & 1012.64 & 1076.60 \\
\hline Oven Drying Temperature, ${ }^{\circ} \mathrm{C}$ & 140 & 140 & 140 & 140 \\
\hline Oven Drying Time, hrs & $\sim 3.5-4$ & $\sim 3.5-4$ & $\sim 3.5-4$ & $\sim 3.5-4$ \\
\hline Silica Gel Mass After Oven Drying, g & 1099.00 & 881.71 & 903.18 & 987.90 \\
\hline Silica Gel Mass After Adsorption, g & 1263.00 & 932.65 & 1017.43 & 1091.97 \\
\hline Total Mass of Moisture Adsorbed, $g$ & 164.00 & 50.94 & 114.25 & 104.07 \\
\hline Experimental Data Sampling Time (10.00s) & 8000 & 2513 & 2752 & 3189 \\
\hline Equivalent Adsorbed Moisture (g) at 2000 Data Sampling Time & 43.39 & 40.54 & 83.03 & 65.27 \\
\hline
\end{tabular}

In Figure 9, profiles of the moisture uptake rate by the packed beds are presented. For each of the packed beds undergoing adsorption, the rate of moisture transfer is given by the rate of change of the weight of the water content in the bed which is also equal to the difference in weight between exit and inlet vapour flow rates ${ }^{32}$ as presented mathematically in equation (6). 
Equation (7) from Lu and Zhao ${ }^{21}$ for the calculation of the real velocity of the bed was used to determine the air mass flow rate, $m_{g}$.

$u=\frac{Q_{v}}{\varepsilon A}$

The results in Figure 9 shows that the overall moisture uptake rate was significantly higher in the FPB than the annulus packed beds over the period of each experiment. For all packed beds, the moisture uptake rate was found to decline over time. This is in line with Awad et al's ${ }^{5}$ assertion that higher rates of adsorption are observed during the first few minutes which decreases as the bed temperature increases. Between the annulus packed beds, it was observed that the MAPB comparatively had a better moisture uptake rate than the SAPB and LAPB. Between the MAPB and the SAPB in Figure (9), it can be observed that at the early stages of the adsorption process, they both had a similar moisture uptake rate before it increased momentarily for the SAPB. Subsequently the MAPB's moisture uptake rate increased showing a comparatively better moisture uptake performance overall. For the LAPB, its moisture uptake rate was comparatively lower in general.

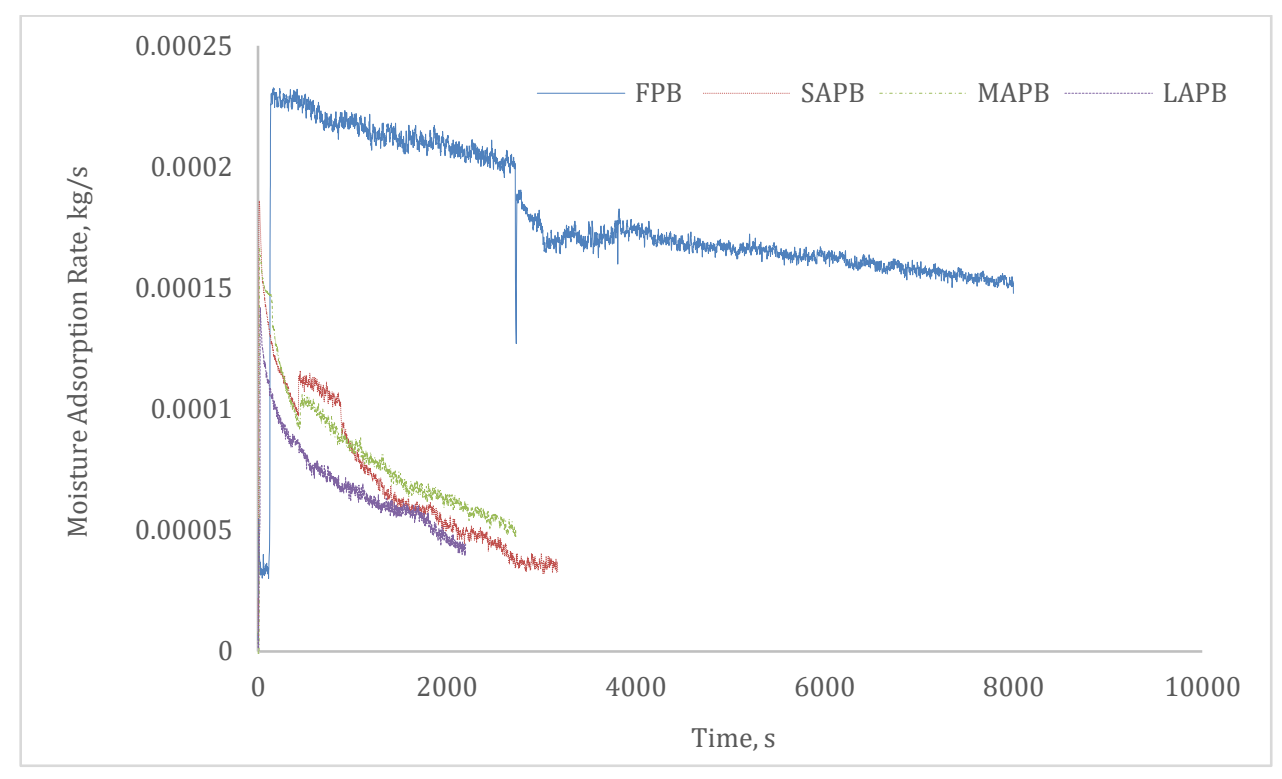

Figure 9 Rate of Moisture Adsorption in Packed Beds

The performance of the packed bed adsorption systems were further evaluated by the percentage of moisture removed, this was determined using the inlet and outlet humidity ratios of the unsaturated moist air applied to equation (8) by Bui et $\mathrm{al}^{33}$.

Percentage of misture removed $=\frac{\left(\omega_{\text {in }}-\omega_{\text {out }}\right)}{\omega_{\text {in }}} \times 100 \%$

In Figure 10, the percentage of moisture adsorbed by the various packed bed systems over the test periods is presented. As can be observed, the moisture adsorption performance was significantly better at the early stages for all packed bed configurations which overtime declined. The decline in moisture adsorption performance was observed to be sharp for the annulus packed bed configurations and gradual for the fully packed bed. The annulus configuration was observed to enhance the radial flow of moisture in the packed beds and hence enhanced the fluid-solid contact for those configurations. It can be observed from Figure 10 that the percentage of moisture removed was over time lower for the LAPB and SAPB than for the MAPB. Although the SAPB had more mass of silica gel for adsorption, the evaluation shows it 
had a lower percentage of moisture removed which speaks directly to how that configuration enhances the adsorption process. For the LAPB, the relatively smaller mass of silica gel particles mean vigorous fluid-solid contact hence that configuration reaching saturation quickly. Its lower percentage of moisture removed directly correlates with its smaller mass of silica gel for the adsorption process. For the SAPB its lower percentage of moisture removed potentially signifies the degree of adsorption enhancement achieved with that configuration. Here, although the annulus dimension aids radial flow, the comparatively larger amount of randomly packed silica gel present appears to limit effective fluid-solid contact as with the SAPB. For the MAPB, the medium annulus dimension allows reasonable enhanced fluid-solid contact with the medium amount of silica gel present in this configuration. For the fully packed bed, although its configuration does not enhance the adsorption process as with the annulus structure, the amount of moisture removed was comparatively larger and this was mainly due to the mass of silica gel particles available for adsorption, residence time of the fluid and the significant length of time it took to reach steady state temperature.

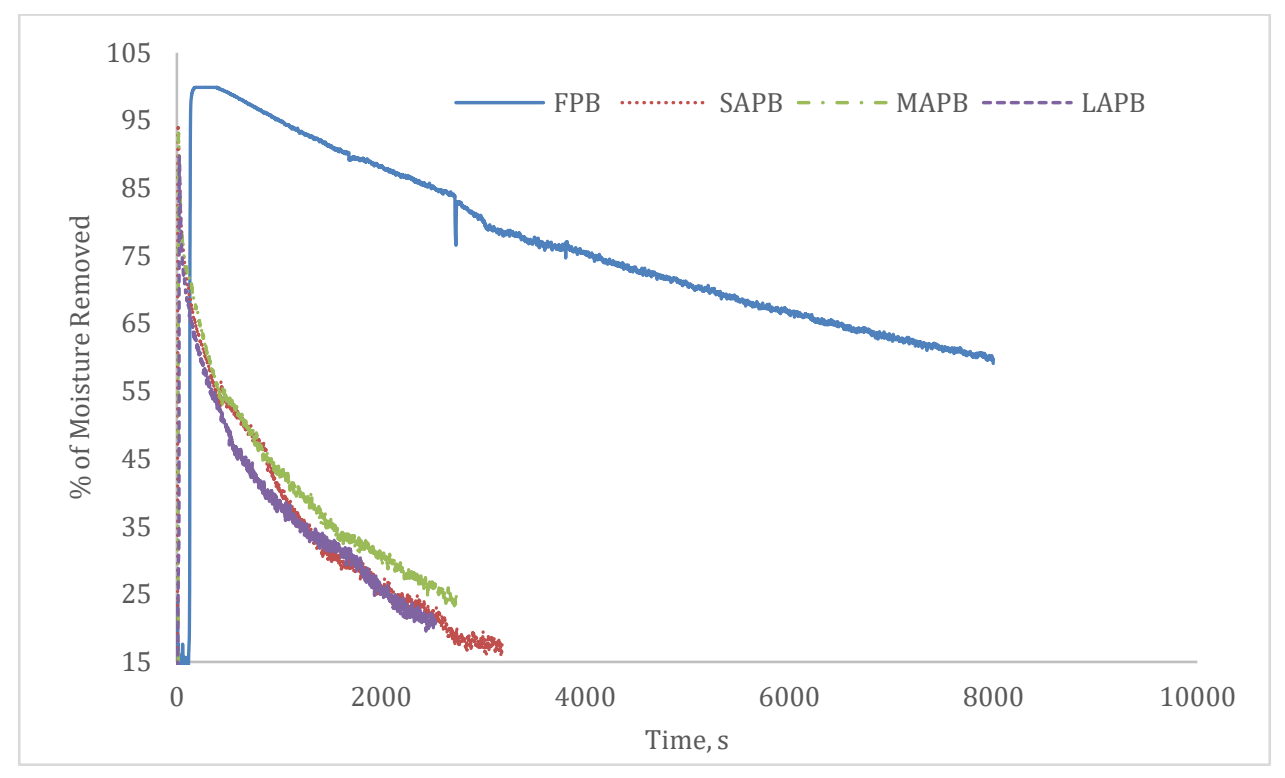

Figure 10 Percentage of Moisture Adsorbed by Silica Gel

To measure the mass of the silica gel particles, the spirit level on the scale balance used was adjusted to ensure it was level before any measurements were carried out. The actual mass of the silica gel was then determined by taring the mass of the container to zero on the scale. The accuracy of these results were contingent on the precision in these measurements, equipment error, human error and the ability to maintain the required condition for the experiments. Although precautions were taken to minimize these errors, the process of measuring the mass of the silica gel after drying before the adsorption process involved transferring the cooled silica gel particles into a container without it being exposed to atmospheric air for adsorption to start outside the vessel. The measurement of the mass of silica gel after the adsorption process also required that the particles were transferred into a container without being exposed to atmospheric air so no changes would occur in the actual amount of moisture adsorbed. Both scenarios mentioned were difficult to achieve to perfection hence may have influenced these results obtained.

\subsection{Bed Outlet Condition}

The outlet temperature and relative humidity values were obtained directly using the AZ8829 sensor and data logger. Figures $11 \mathrm{a}-\mathrm{c}$ presents the outlet conditions for the packed beds. The outlet humidity ratios of the unsaturated moist air were determined in the same way as the inlet humidity ratios using equations (1-3) from CIBSE Guide C24 and Jones ${ }^{25}$. 
In Figure 11a, the outlet humidity ratios profiles shows an initial decline from the inlet condition before subsequent rise with time. For the FPB, the rise in outlet moisture content was gradual over time as it had a comparatively larger mass of silica gel particles and also the random full packing increased the residence time of the fluid in the bed. For the annulus packed beds, the radial distribution of the moist airflow increased the fluid-solid contact thereby allowing enhanced adsorption process leading to a rather increased saturation rate of the adsorbent. From Figure 11a, it can be observed that the outlet moisture content increased with decreasing mass of silica gel. It can also be observed that the outlet moisture content increased as the packed beds approached a steady state temperature condition.

The outlet temperature for the annulus beds followed a similar trend as the average bed interior temperature. At the beginning of the adsorption process the outlet temperatures increased significantly to a peak value before steadily declining (See Figure 11b). For the FPB, the outlet temperature increased from ambient temperature conditions to about $30^{\circ} \mathrm{C}$ before maintaining a relatively steady temperature as the bed temperature also approached steady state temperature. Comparatively, over the investigated periods for the respective packed bed configurations, the FPB outlet airflow temperature was significantly lower. Contrasting the low outlet temperature with the comparatively higher bed temperature goes to suggest that the loose random packing of the FPB significantly limited the airflow through it. The average outlet temperatures were $29.96^{\circ} \mathrm{C}, 32.41^{\circ} \mathrm{C}, 32.53^{\circ} \mathrm{C}$ and $33.05^{\circ} \mathrm{C}$ for the FPB, LAPB, MAPB and SAPB configurations respectively.

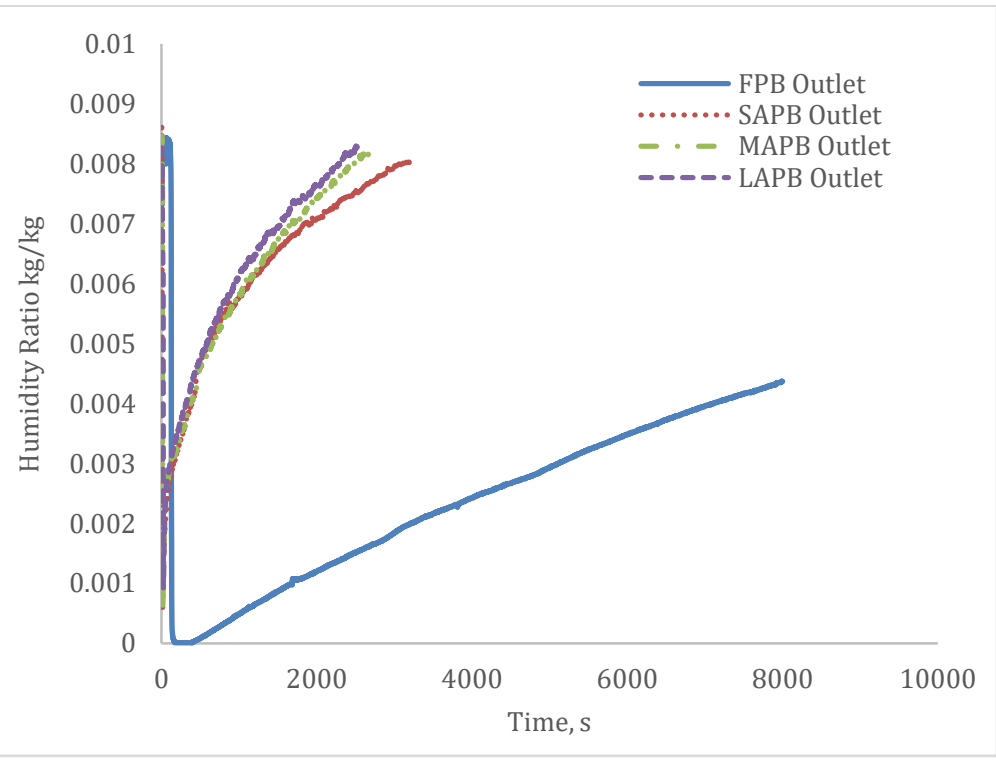

a) Outlet Humidity Ratio

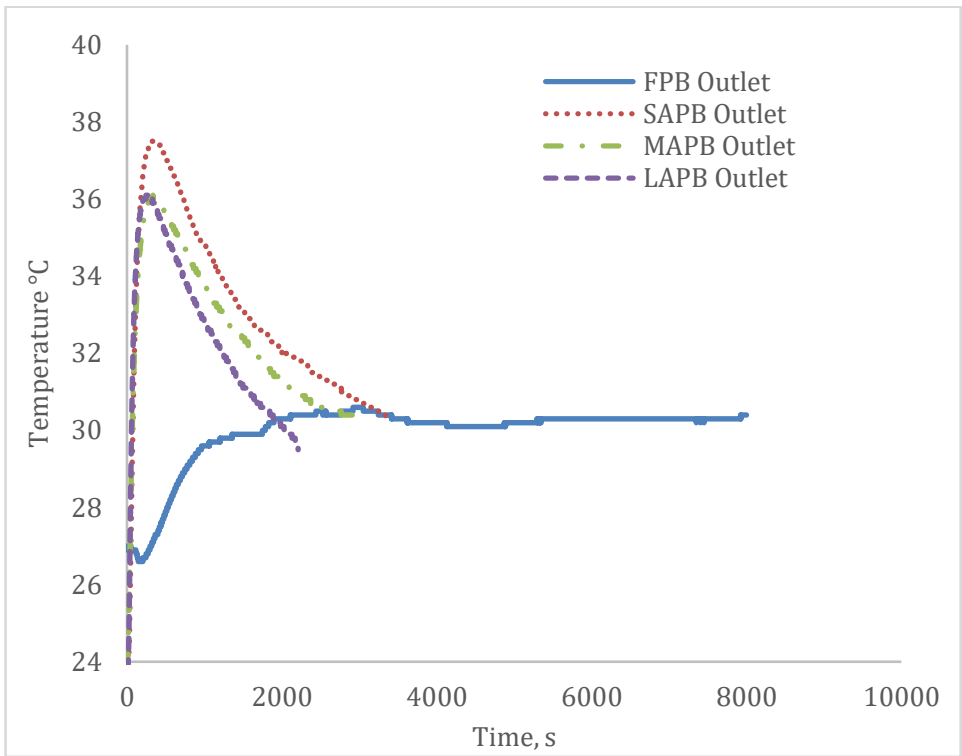

b) Outlet Temperatures 


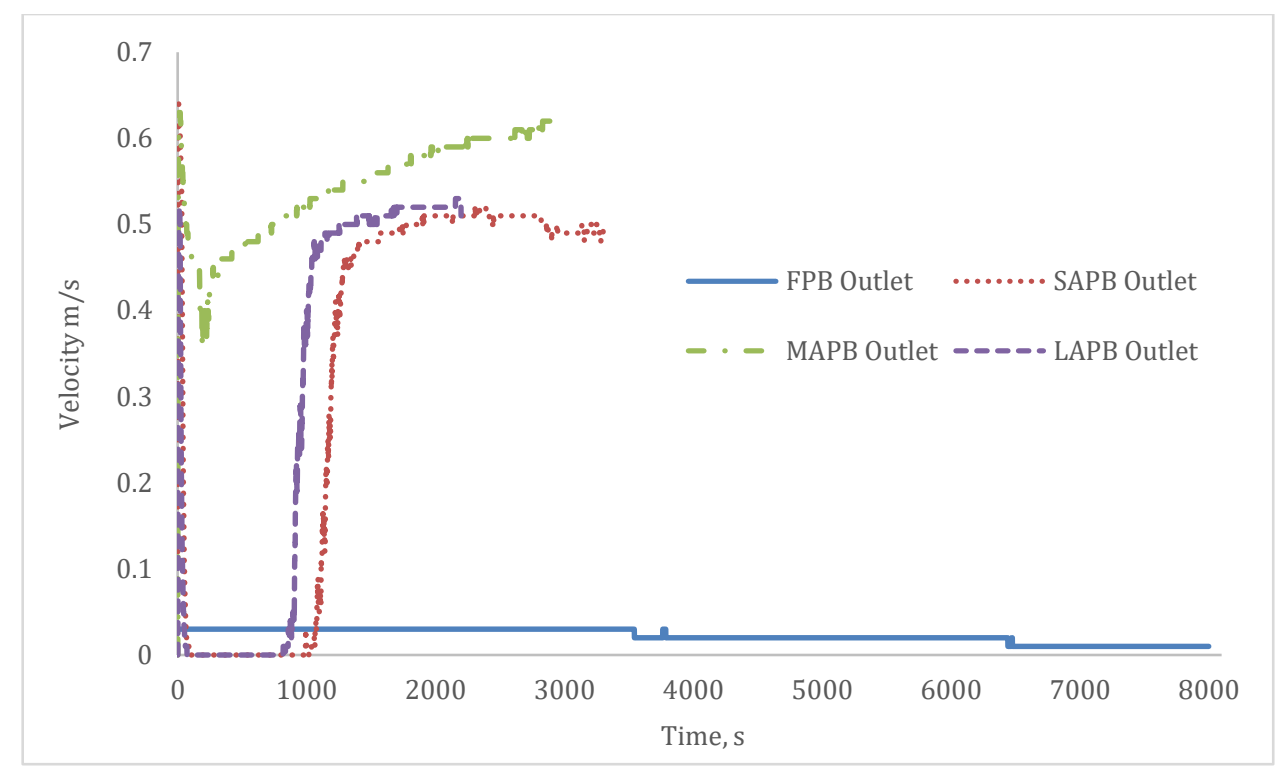

c) Outlet Velocity

Figure 11 Packed Bed Outlet Conditions

Just like the inlet velocity, the outlet velocity was also measured using the Sentry ST 732 Hotwire Anemometer. For the annulus configurations, the outlet velocity initially decreased sharply before steadily rising to a relatively steady state condition (see Figure 11c). This initial dip in the outlet velocities appeared to be as a results of an initial low moist air pressure subsequently building up behind the annulus end plate with the air forcing its way through the packed silica gel in MTZ3 and subsequently the outlet. This was consistent with the fact that the temperatures for the zone of mass transfer increased from MTZ3 to MTZ1. For the FPB, the outlet velocity was relatively steady varying only slightly at some specific points. Also, it was comparatively low, reflective of the non-existence of an annular section for radial flow along, with the full random packing providing a relatively limited pathway for the airflow to exit the bed. This invariably increased the residence time of the moist air in the bed. The average outlet velocities obtained were $0.02 \mathrm{~m} / \mathrm{s}, 0.29 \mathrm{~m} / \mathrm{s}, 0.54 \mathrm{~m} / \mathrm{s}$ and $0.33 \mathrm{~m} / \mathrm{s}$ respectively for the FPB, LAPB, MAPB and SAPB. It can be observed from the average values that the loose random packing in all configurations of the packed bed influenced the outlet velocity. According to Schnitzlein ${ }^{34}$ and Roblee et al ${ }^{35}$, the packing structure causes local velocity fluctuations which influences fluid-mechanical dispersion in the bed.

A possible source of error in the measurement of the inlet and outlet relative humidity and temperature was in the use of the AZ8829 sensor and data logger. Here, the sensors were installed at the inlet and outlet via flexible connection and extension respectively. The possibility of the sensor position being influenced by this arrangement and leading to error was likely. For the Sentry ST732 Hotwire Anemometer, the results obtained was dependent on the position of the sensor and the sensitivity of the sensing element in the flow path.

\section{5. $\quad$ Packed Bed Pressure Drop}

The packing structure for all the configurations was loose and random. For annular packed beds, du Toit ${ }^{8}$ found that the distortion of the packing by the annulus section does not affect the bed porosity in the radial direction. The spherical silica gel particle size used ranged between $4.75-3.35 \mathrm{~mm}$ and resulted in an average bed porosity of 0.44 as determined in Table 3. Pressure data was directly obtained using the QEALY Differential Pressure Meter and the corresponding inlet and outlet gauge pressure differences per unit length presented in Figure 12. From the plot, the pressure drop per unit length for LAPB and MAPB were similar. That for the SAPB and FPB respectively were comparatively lower in that order. 
From the profiles, the MAPB and LAPB plots appear superimposed as they both exhibited similar inlet and outlet pressure values. The pressure profiles observed were typically oscillations of high frequency and amplitude. From Table 9, the average pressure differential was found to increase with increasing annulus dimension. This was because the annulus dimension allowed significant amounts of airflow axially through it, however, the endplate impeded this relatively large axial moist airflow causing flow reversal which subsequently reduced the pressure at the outlet. This invariably created a large pressure differential for this packed bed configuration. It is to be remembered that the Z-annular flow configuration was to ensure radial flow of moist air through the packing, however the determination of the inlet pressure was from the inlet axial flow into the bed. The FPB overall had the lowest inlet pressure. For the Z-annular flow packed beds, the inlet pressures were found to increase with increasing annulus dimension. The magnitude of the resulting pressure drop however, was found to depend on the $\mathrm{D}_{\mathrm{o}} / \mathrm{D}_{\mathrm{i}}$. It is worthy to note that Heggs et $\mathrm{l}^{3}$ also observed that the scale of pressure changes in the annular outlet manifold of the Z-annular flow arrangement was almost three times greater when measured experimentally than when predicted by the model due to local disturbances at the point of measurement giving rise to excessive pressure differences.

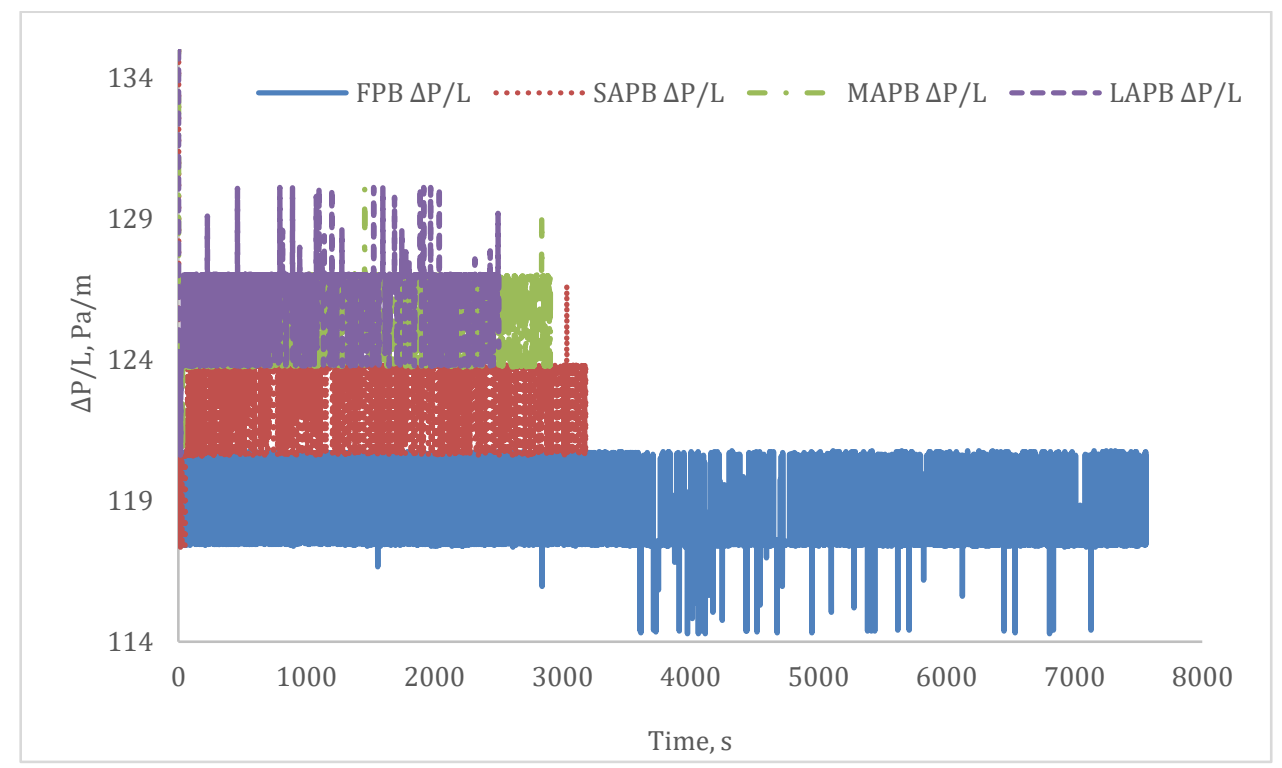

Figure 12 Packed Bed Pressure Drop per Unit Length

\begin{tabular}{|l|l|l|}
\hline \multicolumn{2}{|c|}{ Table 9 Packed Bed Pressure Differential } \\
\hline Packed Bed Type & Average Pressure Difference (Pa) & Average Pressure Drop Per Length of Bed (Pa/m) \\
\hline FPB & 35.47 & 118.25 \\
\hline LAPB & 38.00 & 126.65 \\
\hline$M A P B$ & 37.87 & 126.24 \\
\hline$S A P B$ & 36.97 & 123.23 \\
\hline
\end{tabular}

\subsection{Uncertainty Analysis}

In this present experimental study, the fundamental quantities measured were temperature, relative humidity, pressure and velocity. Table 10 shows the absolute uncertainty of the fundamental quantities for each measurement device. As the measurement devices were digital, the smallest division of measurement was determined as the absolute uncertainty. 


\begin{tabular}{|c|c|c|c|}
\hline \multicolumn{4}{|c|}{ Table 10 Absolute Uncertainty Values for Fundamental Parameters } \\
\hline Parameter & Measurement Device & Absolute Uncertainty & Units \\
\hline Pressure & QEALY Differential Pressure Meter & \pm 0.001 & $\mathrm{~Pa}$ \\
\hline Temperature & Omega K Type Thermocouples & \pm 0.1 & ${ }^{\circ} \mathrm{C}$ \\
\hline Relative Humidity & AZ 8829 sensor and data logger & \pm 0.1 & $\%$ \\
\hline Outlet Velocity & Sentry ST 732 Hotwire Anemometer & \pm 0.01 & $\mathrm{~m} / \mathrm{s}$ \\
\hline Mass & HENGPING Scale Balance & \pm 0.01 & g \\
\hline
\end{tabular}

The percentage/relative uncertainty ${ }^{36}$ was determined from: Percentage Uncertainty $=\frac{\text { Absolute Uncertainty }}{\text { Measured Value }} \times$ $100 \%$. The averages of the percentage uncertainty of the measured fundamental quantities are presented on Table 11 for each packed bed configuration. Here, the uncertainties found in the measurement of the fundamental quantities was mostly inconsequential for the pressure and temperature measurements for all packed bed configuration types. For the FPB, a higher percentage of uncertainty in its measurements of relative humidity and velocity was observed. Generally, for the outlet velocity measurements in all packed bed configurations, the uncertainty was comparatively higher than in the other fundamental quantity measurements.

\begin{tabular}{|l|l|l|l|l|}
\hline \multicolumn{4}{|c|}{ Table 11 Average Percentage Uncertainty Temperature Measurement (\%) } \\
\hline & FPB & LAPB & MAPB & SAPB \\
\hline Pressure & 0.0028 & 0.0026 & 0.0026 & 0.0027 \\
\hline Temperature & 0.12 & 0.13 & 0.13 & 0.13 \\
\hline Relative Humidity & 14.81 & 0.24 & 0.26 & 0.27 \\
\hline Outlet Velocity & 33.33 & 4.24 & 1.95 & 6.07 \\
\hline
\end{tabular}

The mean, the standard deviation and the standard error of the mean for the fundamental quantities were determined in Microsoft Excel and presented in Table 12. As shown, the standard deviation for all the measured quantities except relative humidity was relatively low.

\begin{tabular}{|c|c|c|c|c|c|}
\hline \multicolumn{6}{|c|}{ Table 12 Uncertainty Analysis of the Fundamental Properties } \\
\hline & & FPB & LAPB & MAPB & SAPB \\
\hline \multirow[t]{3}{*}{ Pressure } & Mean & 35.47 & 38.00 & 37.87 & 36.97 \\
\hline & Standard Deviation & 0.46 & 0.25 & 0.22 & 0.31 \\
\hline & Standard Error of the Mean & 0.010 & 0.0056 & 0.0049 & 0.0069 \\
\hline \multirow[t]{3}{*}{ Temperature } & Mean & 42.20 & 37.47 & 38.71 & 39.18 \\
\hline & Standard Deviation & 0.79 & 1.72 & 1.99 & 1.94 \\
\hline & Standard Error of the Mean & 0.018 & 0.038 & 0.044 & 0.043 \\
\hline \multirow[t]{3}{*}{ Relative Humidity } & Mean & 9.16 & 45.69 & 43.52 & 42.67 \\
\hline & Standard Deviation & 2.97 & 9.12 & 8.99 & 7.71 \\
\hline & Standard Error of the Mean & 0.066 & 0.20 & 0.20 & 0.17 \\
\hline \multirow[t]{3}{*}{ Outlet Velocity } & Mean & 0.03 & 0.45 & 0.52 & 0.45 \\
\hline & Standard Deviation & $6.62872 \mathrm{E}-16$ & 0.011 & 0.036 & 0.014 \\
\hline & Standard Error of the Mean & $1.5 \mathrm{E}-18$ & 0.00025 & 0.0008 & 0.00031 \\
\hline
\end{tabular}




\section{Conclusion}

The Heggs et al (1994) Z-annular flow arrangement was used to experimentally investigate its influence on the enhancement of the adsorption process in solid desiccant packed bed dehumidification system. Adsorption performances of solid desiccant packed beds with varied dimensions of the Z-annular flow configuration were compared to that of a fully packed of similar dimensions. The experimental results show that;

- The end plate of the Heggs et $\mathrm{al}^{6} \mathrm{Z}$-annular flow arrangement significantly influenced the inlet air conditions of the annulus packed beds by impeding the flow and causing reversed flow at the inlet.

- For the $\mathrm{Z}$ annulus arrangements, the zone of mass transfer increased with time and counter flow to the direction of the moist airflow. This was as a result of the capped end of the annulus insert impeding the moist airflow and creating turbulent eddies around the capped end thereby increasing the adsorption activity in the mass transfer zone (MTZ3) adjacent to it.

- For the FPB maximum temperature increase was observed in MTZ1 whilst for the annulus configurations the maximum temperature increase was observed in MTZ3. The Z-annular flow configuration enhanced adsorption and also resulted in a decrease in packed bed temperature averaging between $4.22-5.47^{\circ} \mathrm{C}$ less that of the FPB.

- The decline in moisture adsorption observed was sharp for the annulus packed bed configurations due to enhanced adsorption and gradual for the fully packed bed configuration due to a comparatively large mass of silica gel.

- The end plate also influenced outlet conditions by initially causing moist air build up which lowered the outlet velocity initially before the pressure build up forced the air out causing an increase in the outlet velocity. The buildup also increased adsorption activities in MTZ3 leading to an increase in outlet moisture content with time. The initial increase in adsorption activities in MTZ3 also caused an initial outlet temperature increase which declined as MTZ3 approached saturation.

- The Z-annular flow configuration allowed comparatively large inlet pressure due to unimpeded axial flow of moist air from the inlet. However the end plate impeded this flow causing flow reversal which subsequently reduced the outlet pressure resulting in significant pressure drops overall.

Overall, within the limitations of this investigation, the MAPB configuration showed superior enhanced adsorption capacity performance, adsorbing more moisture than the other packed beds over similar period when all packed beds were at relative steady state temperature. This suggests that although the the Heggs et al ${ }^{6} \mathrm{Z}$-annular flow arrangement has the potential to enhance the adsorption capacity of packed beds, there is an optimum dimension where optimum adsorption enhancement can be attained. We therefore recommend that further investigation be carried out to identify optimum parameters for adsorption enhancement using this configuration type.

\section{References}

1 Zhang, Wenli. Thompson, Karsten. E. Reed, Allen H. and Beenken, Liese (2006) Relationship between packing structure and porosity in fixed beds of equilateral cylindrical particles. Chemical Engineering Science, Volume 61, Issue 24, Pages 8060-8074 
Guo, Zehua ., Sun, Zhongning ., Zhang, Nan., Ding, Ming . and Cao, Xiaxin . (2017) Radial porosity peak at the centerline of packed beds with small tube to particle diameter ratios. Powder Technology, Volume 319, September 2017, Pages 445-451

3 Heggs, P.J. Ellis, D.I. and Ismail, M.S. (1995) Prediction of flow distributions and pressure changes in multi-layered annular packed beds. Gas Separation \& Purification, Volume 9, Issue 4, Pages 243-252

$4 \quad$ Kwapinski, Witold. Salem, Karijm. Mewes, Dieter. and Tsotsas, Evangelos (2010) Thermal and flow effects during adsorption in conventional, diluted and annular packed beds. Chemical Engineering Science, Volume 65, Issue 14, Pages 4250-4260

5 Awad, M.M. Ramzy K, A. Hamed, A.M. and Bekheit, M.M. (2008) Theoretical and experimental investigation on the radial flow desiccant dehumidification bed. Applied Thermal Engineering, Volume 28, Issue 1, Pages 75-85

6 Heggs, Peter J. Ellis, David. I. and Ismail, Mohammed. S. (1994) The modelling of fluid-flow distributions in annular packed beds. Gas Separation \& Purification, Volume 8, Issue 4, 1994, Pages 257-264

7 Tierney, M. Nasr, A . and Quarini, G. (1998) The use of proprietary computational fluid dynamics codes for flows in annular packed beds. Separation and Purification Technology, Volume 13, Issue 2, Pages 97-107

8 du Toit, C.G. (2008) Radial variation in porosity in annular packed beds. Nuclear Engineering and Design, Volume 238, Issue 11, Pages 3073-3079

9 Hamed, A.M. Abd-Elrahman, W.R. El-Emam, S.H. and Awad, M.M. (2013) Theoretical and experimental investigation on the transient coupled heat and mass transfer in a radial flow desiccant packed bed. Energy Conversion and Management, Volume 65, Pages 262-271

10 Yeboah, S.K. and Darkwa, J. (2016) A critical review of thermal enhancement of packed beds for water vapour adsorption. Renewable and Sustainable Energy Reviews, Volume 58, Pages 1500-1520

11 McTigue, J.D. and White, A.J. (2017). A Comparison of Radial-flow and Axial-flow Packed Beds for Thermal Energy Storage. Energy Procedia, Volume 105, Pages 4192-4197

12 Iranshahi, Davood., Salimi, Parisa., Pourmand, Zahra., Saeidi, Samrand ., Klemeš, Jiří Jaromír. (2017) Utilising a radial flow, spherical packed-bed reactor for auto thermal steam reforming of methane to achieve a high capacity of $\mathrm{H}_{2}$ production. Chemical Engineering and Processing: Process Intensification, Volume 120, Pages 258-267

13 Kareeri, Aqeel A., Zughbi, Habib H. and Al-Ali, Habib H. Simulation of Flow in a Radial Flow Fixed Bed Reactor (RFBR). June 2005. Conference: 6th International Conference on Computational Fluid Dynamics in the Oil \& Gas, Metallurgical and Process Industries Trondheim, Norway June 2005At: Trondheim. Norway. Volume: Paper 31

14 Pramuang, Surajitr and Exell, R.H.B. (2007) The regeneration of silica gel desiccant by air from a solar heater with a compound parabolic concentrator. Source: Renewable Energy, v 32, n 1, p 173-182.

15 Chang, K.S.C. Wang, H.C. and Chung, T.W. (2004) Effect of regeneration conditions on the adsorption dehumidification process in packed silica gel beds. Appl Thermal Eng, pp. 735-742

16 Sun, J. and Besant, R.W. (2005) Heat and mass transfer during silica gel-moisture interactions. International Journal of Heat and Mass Transfer 48 (23-24), pp. 4953-4962

17 Yang, Ralph T. (2003) Adsorbents: Fundamentals and Applications. John Wiley \& Sons, Inc., Hoboken, New Jersey. ISBN 0-471-29741-0. Pages 79-372

18 Ulku, A.S. and Mobedi, M. (1989) Adsorption in energy storage. B. Kilkis, S. Kakac (Eds.), Energy storage systems, Kluwer Academic Publishers.

19 Atmakidis, Theodoros. and Kenig, Eugeny. Y. (2009) A numerical study on the residence time distribution in low. Chemical engineering transactions. Vol 18. AIDIC Servizi S.r.l, ISBN 978-88-95608-04-4 ISSN 1974-9791. DOI:103303/CET0918094 


\section{adsorption/d}

24 122

34 Category: 59c

LeVan, M. Douglas, Carta, Giorgio and Yon, Carmen M. (1997) Adsorption and Ion Exchange. In: Green, Don W. and Perry, Robert H. (2007). Perry's Chemical Engineers' Handbook (7th Edition). McGraw-Hill.

Lu, G.Q. and Zhao, X.S. (2004) Nanoporous Materials - Science and Engineering. World Scientific.

CIBSE Guide A (2006) Environmental design. 7th edition. The Chartered Institution of Building Services Engineers London. ISBN-10: 1-903287-66-9

CIBSE Guide C (2007) reference data. The Chartered Institution of Building Services Engineers London.

Jones, W.P. (2005) Air Conditioning Engineering. Fifth Edition. Butterworth Heinemann, Pp 30-33

Cengal, Yunus. A. and Ghajar, Afshin. J. (2011) Heat and Mass Transfer: Fundamentals and Applications. Fourth Edition in SI Units. McGraw Hill. Pp 7-11

Fahien, R. W. and Smith, J. M. (1955), Mass transfer in packed beds. AIChE Journal, 1: 28-37. doi: 10.1002/aic.690010104

Barlow, Robert. S. (1982) Analysis of the Adsorption Process and of Desiccant Cooling Systems - A Pseudo- SteadyState Model for Coupled Heat and Mass Transfer. Solar Energy Research Institute. A Division of Midwest Research Institute. Prepared Under Task No. 1131.00 and 1 f 32.11. WPA Nor 01-256 and 01-315. SERI/TR-631-1330. UC

Ramzy, A. K.,Kadoli, R. and Ashok Babu, T.P. (2010) Improved utilization of desiccant material in packed bed dehumidifier using composite particles. Renewable Energy, Volume 36, Issue 2, Pages 732-742

Hamed, A.M. (2005) Experimental investigation on the adsorption/desorption processes using solid desiccant in an inclined-fluidized bed, Renewable Energy 30, pp. 1913-1921

Nic An tSaoir, Méabh. Fernandes, Daniel Luis Abreu. Jacinto Sá, McMaster, Michael. Kitagawa, Kuniyuki. Hardacre, Christopher. and Aiouache, Farid (2011) Visualization of water vapour flow in a packed bed adsorber by nearinfrared diffused transmittance tomography. Chemical Engineering Science, Volume 66, Issue 24, Pages 6407-6423

Kabeel, A. E. (2009) Adsorption-desorption operations of multilayer desiccant packed bed for dehumidification applications. Renewable Energy, Volume 34, Issue 1, January 2009, Pages 255-265

Bui, Thuan Duc. Chen, Feng. Nida, Aqdas. Chua, Kian Jon. and Ng, Kim Choon (2015) Experimental and modeling analysis of membrane-based air dehumidification. Separation and Purification Technology, Volume 144, Pages 114-

Schnitzlein, K. (2001) Modelling radial dispersion in terms of the local structure of packed beds. Chemical Engineering Science, Volume 56, Issue 2, Pages 579-585

35 Roblee, L. H. S., Baird, R. M. and Tierney, J. W. (1958), Radial porosity variations in packed beds. AIChE J., 4: 460464. doi: 10.1002/aic.690040415

Potts, John and Devlin, John. Propagation of Experimental Uncertainties 1. Available at:

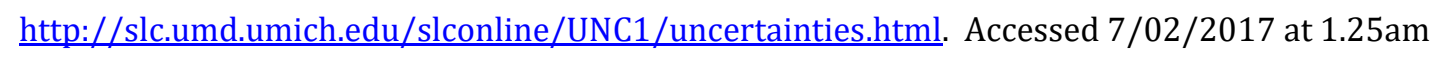

